\title{
REGULATORY-FRAMEWORK-EMBEDDED ENERGY \\ MANAGEMENT SYSTEM FOR MICROGRIDS: THE CASE STUDY OF THE SPANISH SELF-CONSUMPTION SCHEME
}

Please, cite this article as:

Jordi de la Hoz, Helena Martín, Alex Alonso, Adriana Carolina Luna, José

Matas, Juan C. Vásquez, Josep M. Guerrero. Regulatory-framework-

embedded energy management system for microgrids: The case study of

the Spanish self-consumption scheme. Applied Energy, Volume 251, 2019, 113374, ISSN 0306-2619

https://doi.org/10.1016/j.apenergy.2019.113374 


\title{
REGULATORY-FRAMEWORK-EMBEDDED ENERGY MANAGEMENT SYSTEM FOR MICROGRIDS: THE CASE STUDY OF THE SPANISH SELF-CONSUMPTION SCHEME
}

\author{
Jordi de la Hoz ${ }^{\mathrm{a}, \mathrm{c}_{*}}$, Helena Martín ${ }^{\mathrm{a}, \mathrm{c}}$, Alex Alonso ${ }^{\mathrm{b}, \mathrm{c}}$, Adriana Carolina Luna ${ }^{\mathrm{d}, \mathrm{e}}$, José Matas ${ }^{\mathrm{a}, \mathrm{c}}$, \\ Juan C. Vasquez ${ }^{d}$, Josep M. Guerrero ${ }^{d}$ \\ ${ }^{a}$ Department of Electrical Engineering \\ ${ }^{\mathrm{b}}$ Student of the Bachelor's Degree in Energy Engineering \\ ${ }^{\mathrm{C}}$ Universitat Politècnica de Catalunya (UPC) \\ Escola d'Enginyeria de Barcelona Est (EEBE) \\ C/ Eduard Maristany, 10-14, 08019 Barcelona \\ ${ }^{d}$ Department of Energy Technology, Aalborg University, 9220 Aalborg, Denmark \\ ${ }^{\text {e } U n i v e r s i d a d ~ d e ~ l o s ~ A n d e s, ~ C o l o m b i a ~}$ \\ *Corresponding author. Tel.: +34 934137 319; fax: +34 934137401 \\ E-mail address: jordi.de.la.hoz@upc.edu (J. de la Hoz)
}

\begin{abstract}
This paper proposes for the first time to analyse the impact of embedding the regulatory framework constraints inside a model for the energy management optimization of a microgrid. As a case study, a low voltage microgrid using solar energy under the Spanish selfconsumption scheme has been selected. The proposed model is based on a previous one elaborated by the authors, which did not include the regulatory framework. The results provided by the former and the new model have been compared, corroborating the importance of taking into account the economic aspects of the regulatory constraints when managing the facility. Furthermore, the results also highlight the urgency to extrapolate this approach to other countries, in order to enhance the economic feasibility of these facilities and aid to their deployment. In addition, the performance of the model has been experimentally validated at the Microgrid Research Laboratory of Aalborg University.
\end{abstract}




\section{Keywords}

Self-Consumption, microgrid, energy management, regulatory framework

\section{Introduction}

The European Union's (EU) energy policy has made it a world leader in the promotion of renewable energy [1]. The consumer rights and protection are a crucial part of this policy. In this regard, the EU is currently working to guarantee that the European consumers may have the right to produce, store, consume, and resell their self-generated electricity to the grid. In fact, self-consumption is nowadays a reality in a significant part of the EU countries and around the world [1]. It is expected to be a promising tool to promote renewable energy in the tertiary and domestic sectors, with microgrids being an intrinsic part of the self-consumption facilities.

Hereof, research on microgrids has deserved special attention in these last decades, and some recent studies have focused on reviewing their evolution. Some of these reviews provide a holistic view of the microgrid concept and allow to see its intricacies [2], while others focus their attention on specific parts or processes, such as energy management systems (EMS) of microgrids $[3,4]$. In this regard, an update on the state of the art of the EMS has been here conducted, elaborating on the studies [3, 4]. This update includes both new articles and some older ones not covered by the aforementioned reviews. The resulting upgraded state of the art is shown in Table 1.

Table 1. State of the art of microgrid research. Source: self-elaboration based on $[3,4]$.

The rows of Table 1 are grouped into two sections. Whereas the upper rows contain references using single objective optimisation (SOO), the lower rows collect those with a multi- 
Table 1. State of the art of microgrid research. Source: self-elaboration based on [3, 4].

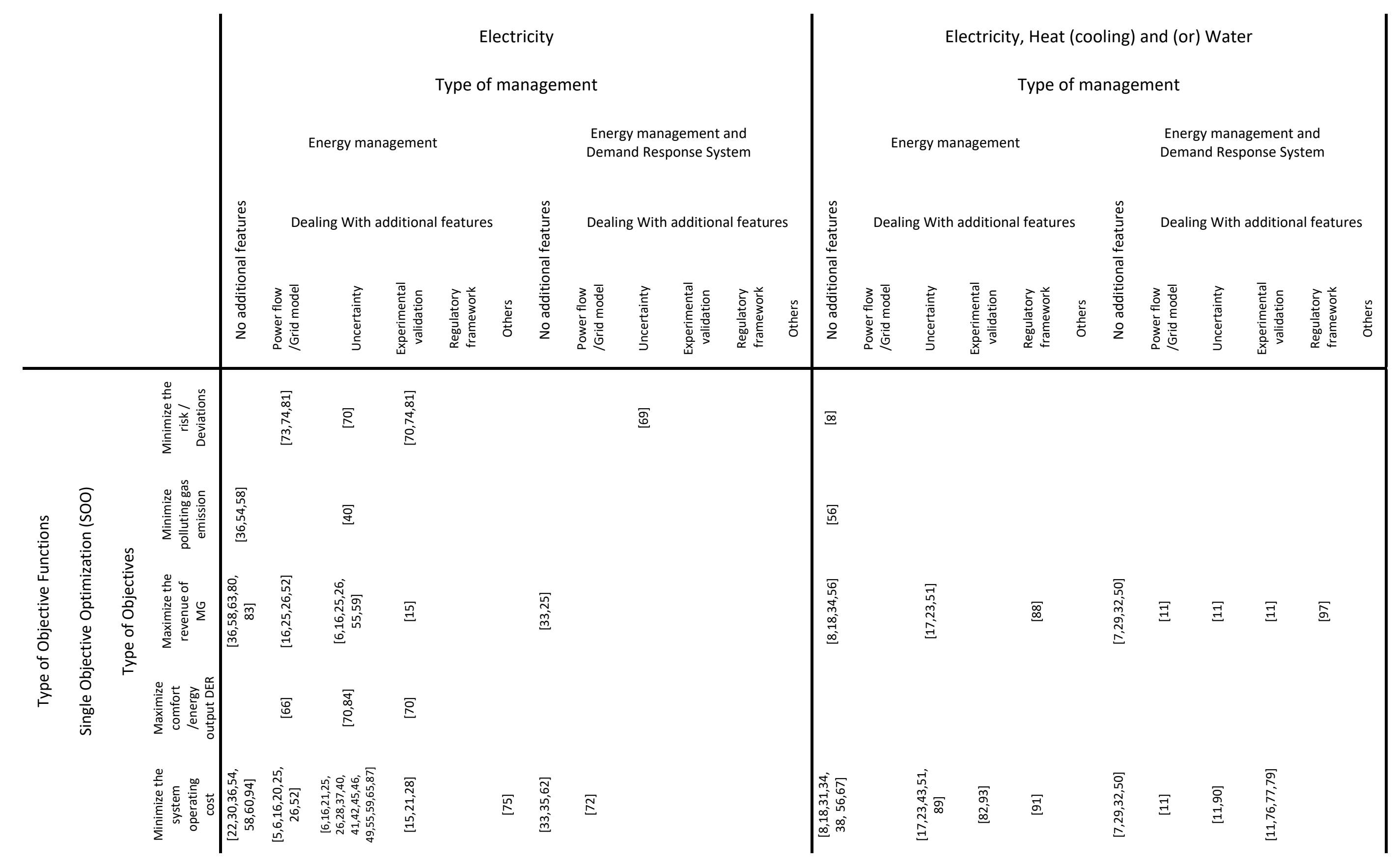




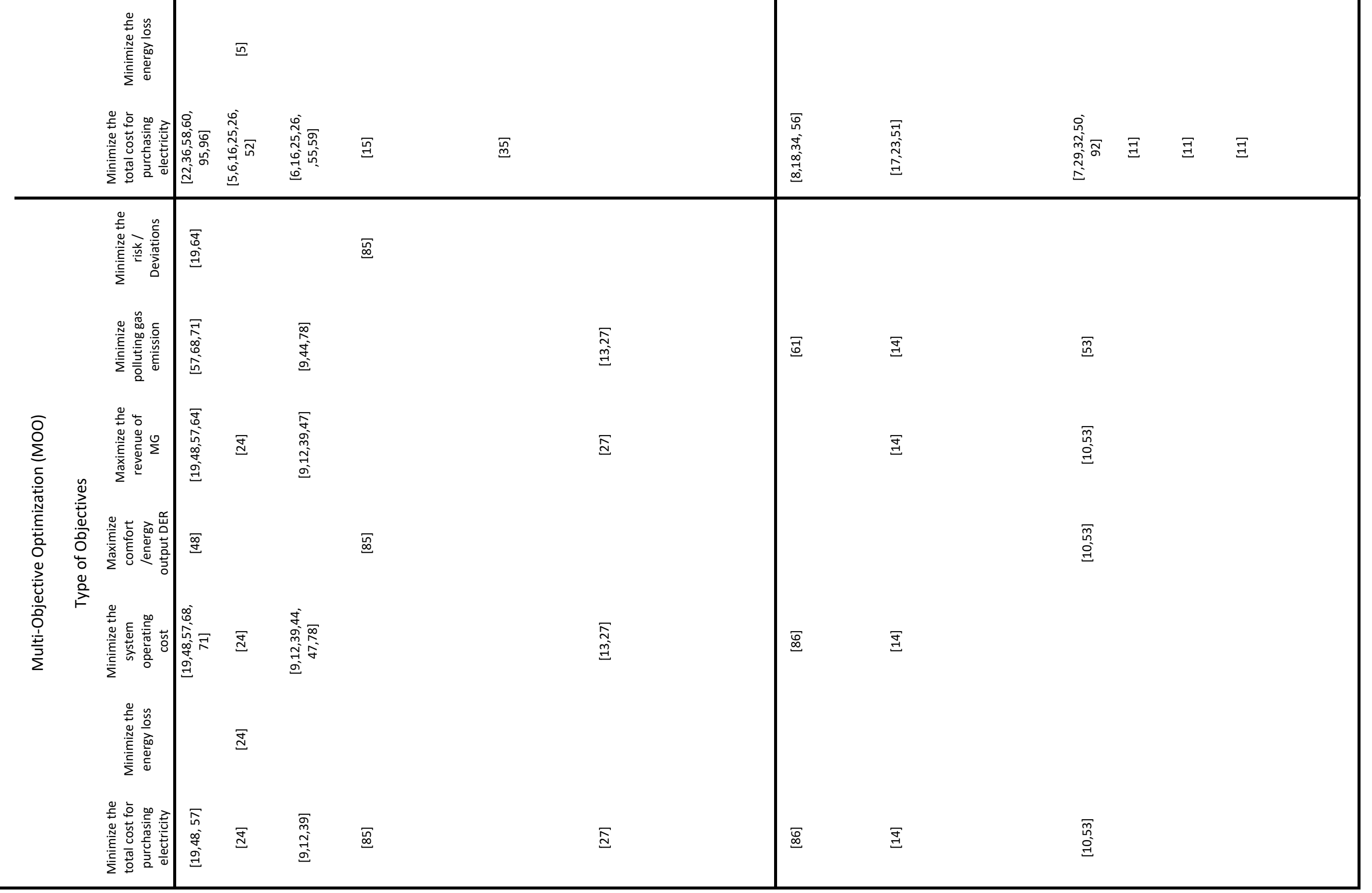


This accepted manuscript does not include other publisher value-added contributions such as copy-

editing, formatting, technical enhancements and (if relevant) pagination.

objective optimisation (MOO) approach. Both the SOO and the MOO sections of Table 1 are further divided into new subsections containing the most relevant objective functions identified in [3]. Likewise, the columns of Table 1 are grouped into two sections. The columns on the left side include references considering a single energy vector (electricity), while the columns on the right side gather those using multiple energy vectors (electricity, heating/cooling and/or water). In turn, a second level of classification is established in each of the single/multiple energy vector sections, according to the implementation or not of a demand response system in the microgrid EMS. Finally, the references are sorted depending on whether additional features such as grid model, uncertainty, experimental validation, regulatory framework, etc., are considered.

As can be seen in Table 1, SOO prevails over the MOO approach. Regarding the objective function type, the minimisation of the system operating cost is the most spread, followed by the minimisation of the energy purchasing cost and the maximisation of the revenue of energy selling. At all events, economic considerations in the objective function predominate over the environmental issues. On the other hand, electricity is the only energy vector considered by over $65 \%$ of the references, and $78 \%$ of the studies do not contemplate the use of a demand response system when managing the energy system. Also, $58 \%$ of the references include some of the listed additional features in their models. In this regard, $38 \%$ of the studies opted for incorporating uncertainty in their analyses.

Nevertheless, to the authors' knowledge and according to the state of the art in Table 1, $97 \%$ of the analysed research don't incorporate in their algebraic models the regulatory constraints. This is at least surprising considering the deep impact of the regulatory frameworks in the economic performance of the energy assets [98, 99]. Even though the energy sector is highly regulated, only a few articles $[88,91,97]$ contemplated the use of regulatory constraints in their models, but they did not analyse neither their impact nor their importance. As a result, the lack of studies elucidating the influence of regulatory constraints on energy management results may induce to think that there is no need to incorporate such limitations in the models. To overcome this gap, the article is aimed to give clear evidence that regulatory framework 
This accepted manuscript does not include other publisher value-added contributions such as copy-

editing, formatting, technical enhancements and (if relevant) pagination.

constraints alter the optimal energy management of a microgrid. To do so, a model used in previous works $[59,60]$ has been modified in order to consider the regulatory framework applied to a consumer owning a microgrid. In addition, the characterisation of the regulatory framework has been realised accurately, not just conceptually. Concerning this, the Spanish regulatory framework has been selected for this study as it is considered one of the most complex systems in the EU countries, either due to its energy contracts or to the self-consumption scheme applied to consumers.

To this end, the paper provides a description of the energy contracts and the selfconsumption regulatory scheme applied to low voltage consumers in Spain (section 2). Next, the research methodology is introduced (section 3) and the model addressing the regulatory framework (section 4) is described. Then, a case study is undertaken, and the obtained results are experimentally validated at the Microgrid Research Laboratory of Aalborg University (section 5) [100]. Finally, all the factors deemed relevant are duly systematised, and conclusions are raised (section 6).

\section{Setting the context}

\subsection{Energy bill structure for low voltage consumers}

Low voltage consumers not exceeding $10 \mathrm{~kW}$ are allowed to choose between two types of energy contracts, either those under the Royal Decree (RD) 216/2014 [101] (a sort of energy contract with regulated energy prices) or those under the rules of the liberalised energy market. The rest of low voltage and all the high voltage consumers are forced to hire energy in the liberalised energy market. In all cases, the resulting cost for a consumer is a function of the energy cost and the access tariff cost. In this article, the attention will be focused on the energy contracts in the liberalised energy market, as they are the common case of energy contracts applicable to all type of energy consumers. 
In Spain, the energy cost is the result of three processes, i.e., the cost of producing energy in the Iberian Electricity Market (IEM) (subjected to the RD 2019/1997 [102] and the Day-Ahead and Intraday Electricity Market Operating Rules of May 2018 [103]), the energy transport and distribution losses and the economic margin of the retailer.

Regarding the cost of producing energy in the IEM, sale and purchase bids are made one day ahead, considering between 1 and 25 energy blocks with their respective power and energy prices offers for each hour of the day. For purchase bids, preference is given to those bids that have the highest energy prices. For sale bids, it is quite the opposite. As a result, a marginal price is determined for each hour of the following day, called the daily market price $\left(P m_{h}\right)$. Nevertheless, this price is increased due to the cost of all the required services addressed to guarantee the energy supply (technical constraints, ancillary services, capacity payments, etc.), resulting in a final price called average hourly final price.

Due to the energy losses of the grid, a loss coefficient increasing the energy price is applied to the energy consumption according to the voltage level and the rated power of the consumers. Additionally, the commercial margin of the retailer is charged to the consumers, giving as a result, the final energy purchased price $\left(f_{e p p}\right)^{1}$. In this regard, the hourly demand of the consumer $\left(D H_{h}\right)$ is calculated according to this final energy purchased price, resulting in the energy cost (see Figure 1).

The other significant term in the energy bill is the access tariff cost to the grid. In this regard, (article 16 of the Law 24/2013 [104] of the Spanish Electricity Sector (LSES)) the access tariffs are applied to energy consumers to guarantee the incomes of the Spanish Electricity Sector (SES) and the retribution of the regulated activities (mainly, transport and distribution and the specific retribution of renewable energy). According to the RD 1164/2001 [105] and its

\footnotetext{
${ }^{1}$ Depending on the type of contract, this energy price might be charged to the consumer either in form of fixed rate (i.e., the energy price remains stable throughout all the hours of the day and month) or variable rate (the energy price may change depending on the period of the day, or from month to month, etc.) or indexed to the IEM (pass-through). In this study, it was assumed that the consumer's facility had an indexed contract as it is the type of contract where the variation of the energy prices in the IEM might be easily translated into economic decisions for the consumer.
} 
This accepted manuscript does not include other publisher value-added contributions such as copy-

editing, formatting, technical enhancements and (if relevant) pagination.

subsequent amendments, all the consumers of the SES are classified according to their voltage level and rated power. Each group has its corresponding type of access tariff, which, at the same time, is composed by two terms, i.e., the energy term and the power term. The consumer will be charged for the energy consumption and the rated power according to the energy term (AE_Grid) and to the power term (AP_Grid), respectively (see Figure 1).

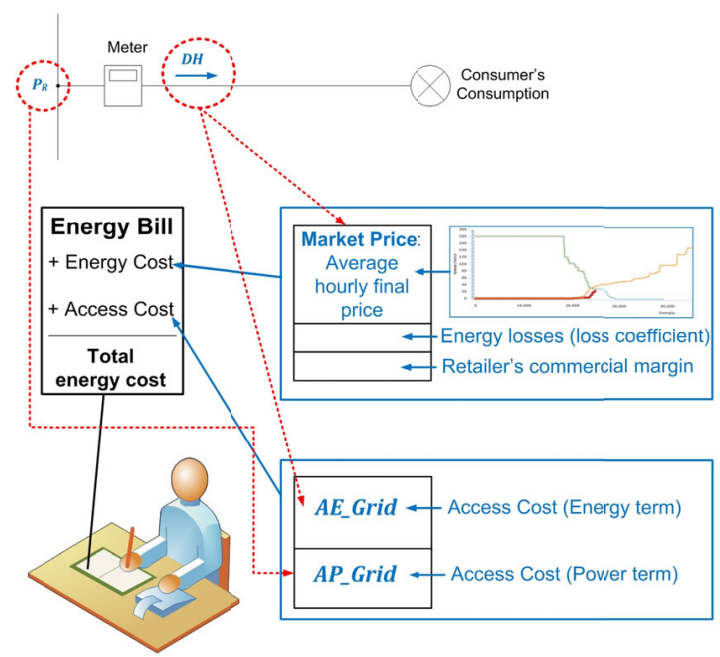

Figure 1. Conceptual definition of the consumer's total energy cost. Source: Self-elaboration.

\subsection{Describing 2015-2018 RD 900/2015 self-consumption regulatory framework applied to low voltage premises}

Article 9 of the LSES enabled consumers to produce and consume their own generated electricity. Nevertheless, it was not until 2015 when the economic scheme applied to selfconsumption became a reality by virtue of the RD 900/2015 [106].

The RD 900/2015 defines two types of self-consumption economic schemes, i.e., Type I and Type II schemes. While the Type II scheme allows the consumer to sell the produced energy to the market, for Type I any excess generated energy injected into the grid will not be rewarded anyhow. 
This accepted manuscript does not include other publisher value-added contributions such as copy-

editing, formatting, technical enhancements and (if relevant) pagination.

Only consumers' facilities with rated power $\left(P_{R}\right)$ equal or less than $100 \mathrm{~kW}$ are authorised to opt for Type I scheme. Conversely, all the consumers (regardless their $P_{R}$ ) may opt for the Type II scheme. Nevertheless, for both schemes the rated power of the generation facility $\left(P V G_{N}\right)$ cannot exceed the $P_{R}$ of the consumer's facility:

$$
P V G_{N} \leq P_{R}
$$

When the consumer's $P_{R}$ is less than $100 \mathrm{~kW}$, the electric scheme will be the same for either Type I or Type II economic schemes (see Figure 2). As can be seen, the only smart meter that is shown in Figure 1 remains connected in Figure 2, after the point of common coupling of the facility. Besides, according to RD 900/2015 (article 11 and tenth transitory disposition) the energy storage system (ESS), if any, is forced to share the meters and protections of the generation facility. As a result, there are two differentiated power lines in a self-consumption facility, one related to consumption and the other related to power generation.

When comparing Figure 1 and Figure 2 it is easy to realise that the self-consumption regulatory framework has introduced an amendment in the consumer's bill due to the existence of the so-called self-consumption charges. These charges were first introduced by article 16 of the $\mathrm{LSES}^{2}$ to mitigate the economic impact regarding income reduction for the SES that selfconsumption might produce. In particular, self-consumption in Spain is taxed by means of two types of charges ${ }^{3}$, namely, the charges related to the cost of the SES (fixed charges and variable charges) and the charges related to other system services.

In brief, some of the intricacies and complexity between the measures and the charges are depicted in Figure 2. As it can be seen, all charges are related somehow to the measurements of meters 1 and 2, either regarding power or energy.

\footnotetext{
${ }^{2}$ As well as RD 900/2015, articles 17 and 18.

${ }^{3}$ RD 900/2015, articles 17 and 18.
} 


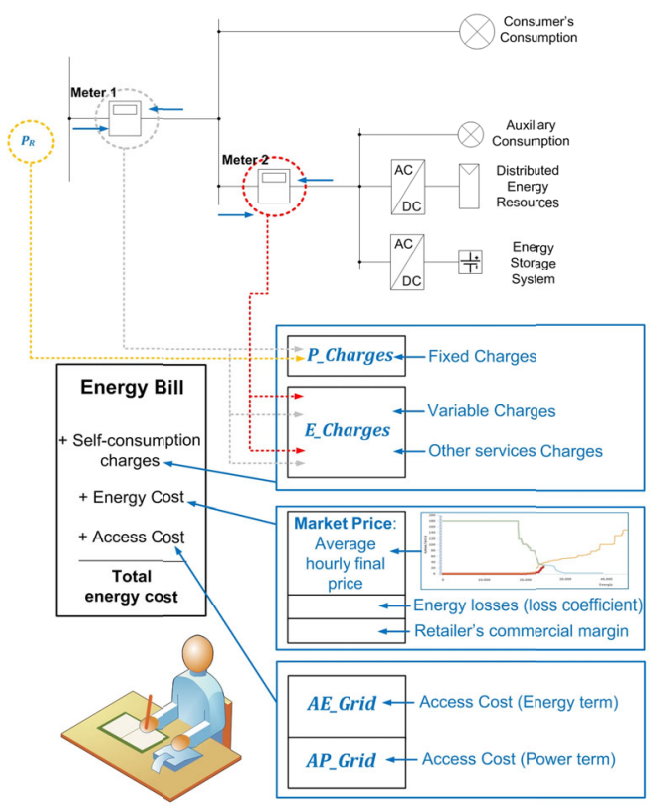

Figure 2. Electric scheme and conceptual definition of the energy cost for a generalised low voltage consumer with a Type I self-consumption facility. Source: Self-elaboration based on [106].

\section{Applied methodology}

A representation of the different stages followed in this study is made in Figure 3. After the analysis of the Spanish self-consumption regulatory framework, a new EMS model able to consider the regulatory restrictions introduced by the RD 900/2015 was developed. In this model, the formulation of the physical elements of the facility was based on a former model used by the authors in a previous study [60]. To compare how the constraints related to the selfconsumption regulatory framework might alter the energy management of a microgrid, a case study of a low voltage facility with a rated power less than $10 \mathrm{~kW}^{4}$ was undertaken. In the case study, the optimal energy management of the energy asset was determined by using both the

\footnotetext{
${ }^{4}$ According to the First Transitory Disposition of RD 900/2015, facilities under the Type I self-consumption scheme with $P_{R}$ not exceeding $10 \mathrm{~kW}$ are exempt to pay the variable charges. Despite this fact, as a worst-case scenario, most companies promoting and installing facilities under the self-consumption scheme do not consider this exemption when analysing the economic results of the energy asset (due to the "transitory" characteristics of this Disposition). In the same way, the study here conducted does not contemplate this exemption in the new model formulation.
} 
This accepted manuscript does not include other publisher value-added contributions such as copyediting, formatting, technical enhancements and (if relevant) pagination.

former and the new energy management models. The results of the two models were compared to determine the effects of the self-consumption regulatory framework on the energy management of the microgrid. Next, an experimental validation was conducted to corroborate the theoretical results, and finally, a set of conclusions regarding the research study were drawn.

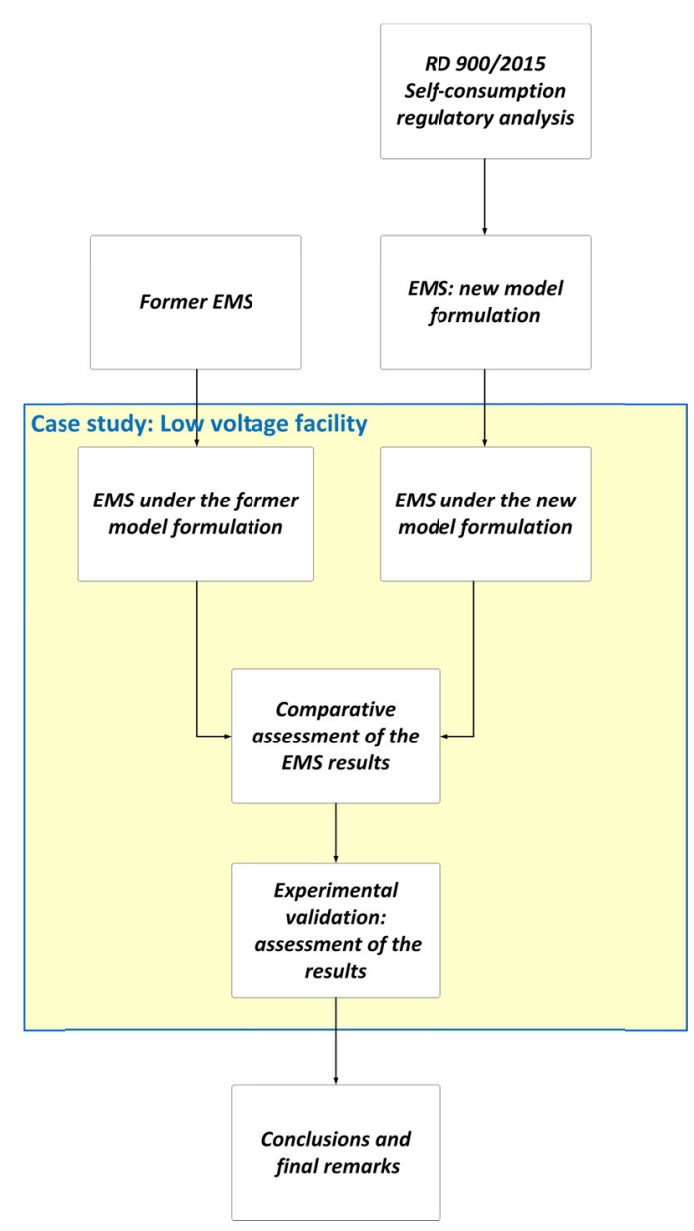

Figure 3. Methodology applied in the research study. Source: Self-elaboration. 


\section{New model description}

\subsection{New model with self-consumption regulatory restrictions}

The new model is based on a previous authors' work [60] and it is defined in time discrete values, with $h$ being the elementary unit of time within the range of twenty-four hours $h=1,2, \ldots$, 24 and $24 \cdot \Delta h$ its time horizon. The main variables of the model are depicted in Figure 4 , and its central intrinsic relations are stated in the following.

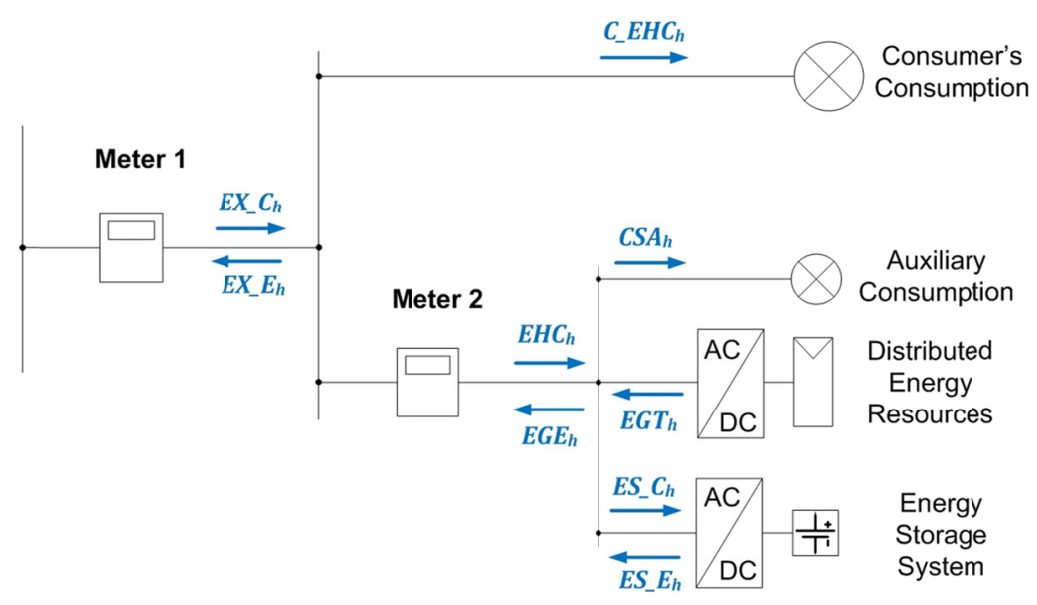

Figure 4. Electrical scheme according to RD 900/2015 for a low voltage consumer with rated power equal or less than 100kW. Source: Self-elaboration based on [106]

a) Energy balance

The formulation of the energy balance is consistent with the definitions and the electrical scheme stated by the RD 900/2015. As can be seen in Figure 4, two complementary energy balances can be formulated at the nodes after the meters 1 and 2 :

$$
\begin{aligned}
& E X_{-} C_{h}+E G E_{h}=C_{-} E H C_{h}+E H C_{h}+E X_{-} E_{h}, E X_{-} C_{h}, E G E_{h}, C_{-} E H C_{h}, E H C_{h}, E X_{-} E_{h} \geq 0, \forall h \\
& E H C_{h}+E S_{-} E_{h}+E G T_{h}=E G E_{h}+E S_{-} C_{h}+C S A_{h}, E S_{-} E_{h}, E G T_{h}, E S_{-} C_{h}, C S A_{h} \geq 0, \forall h
\end{aligned}
$$


This accepted manuscript does not include other publisher value-added contributions such as copy-

editing, formatting, technical enhancements and (if relevant) pagination.

with $E X_{-} C_{h}$ being the aggregated hourly consumption of the overall facility, $E X_{-} E_{h}$ the aggregated hourly injected energy into the grid, $C_{-} E H C_{h}$ the aggregated hourly consumption of the consumer, $E H C_{h}$ and $E G E_{h}$ the aggregated hourly consumption and the aggregated net hourly generation related to the power generation line of the facility, $C S A_{h}$ the aggregated hourly auxiliary consumption related to the RES and the ESS, $E G T_{h}$ the aggregated net hourly generation related to the RES, and $E S_{-} C_{h}$ and $E S_{-} E_{h}$ the aggregated hourly charged and discharged energy in the entire set of the ESS, respectively.

b) Generation

$E G T_{h}$ in eq. (4) is calculated as:

$$
E G T_{h}=\sum_{t} E G T_{t, h}, E G T_{h} \geq 0, \forall h
$$

The new model contemplates a set of renewable energy sources (RES) present in the microgrid, with index $t$. The energy supplied by the RES $t$ at a particular hour $h\left(E G T_{t, h}\right)$ is defined according to the following equations:

$$
\begin{gathered}
E G T_{t, h}=P G T_{t, h} \cdot \Delta h, E G T_{t, h}, P G T_{t, h} \geq 0, \forall t, h \\
P G T_{-} M \operatorname{Mx}_{t} \geq P G T_{t, h}, \forall t, h \\
P G T_{-} \text {curt }_{t, h}=P G T_{-} \text {Max }_{t}-P G T_{t, h}, P G T_{\text {curt }} t, h \\
\text { P }
\end{gathered}
$$

Where $P G T_{t, h}$ is the power provided by the RES $t$ within the hour $h, P G T_{-} M_{a x} x_{t, h}$ is the maximum value of $P G T_{t, h}$, and $P G T_{-} c u r t_{t, h}$ is the power curtailed from PGT_Max $t_{t, h}$ for the RES $t$ within the hour $h$.

\section{c) Storage}

Concerning the storage system, there is a set of different types of ESS present in the microgrid, with index ts. Nevertheless, the storage formulation in the new modelchanged compared to the previous model in [60]. The expression of the state of charge $\left(S_{0} C_{t s, h}\right)$ for the 
ESS $t s$ within the hour $h$ was modified by adding two new variables $P S_{-} C_{t s, h}$ and $P S_{-} E_{t s, h}$, which are, respectively, the power charge and discharge of the ESS ts within the hour $h$. According to this $S o C_{t s, h}$ is defined as:

$$
S o C_{t s, h}=S o C_{t s, h-1}+\frac{P S_{-} C_{t s, h}-P S_{-} E_{t s, h}}{P S T_{-} N_{t s}}, S o C_{t s, h}, P S_{-} C_{t s, h}, P S_{-} E_{t s, h} \geq 0, \forall t s, h
$$

Where $P S T_{-} N_{t s}$ is the nominal power of the ESS $t s$, In this regard, the SoC is forced at the end of the time horizon to be equal to or greater than its initial value:

$$
\sum_{h=1}^{23}\left(S o C_{t s, h+1}-S o C_{t s, h}\right) \geq 0, \forall t s, h \leq 23
$$

$E S_{-} C_{h}$ and $E S_{-} E_{h}$ are calculated as:

$$
\begin{aligned}
& E S_{-} C_{h}=\sum_{t s} E S_{-} C_{t s, h}, E S_{-} C_{h} \geq 0, \forall h \\
& E S_{-} E_{h}=\sum_{t s} E S_{-} E_{t s, h}, E S_{-} E_{h} \geq 0, \forall h
\end{aligned}
$$

with $E S_{-} C_{t s, h}$ and $E S_{-} E_{t s, h}$ being the energy charged and discharged, respectively, to the ESS ts within the hour $h$, which are calculated as:

$$
\begin{array}{r}
E S_{-} C_{t s, h}=P S_{-} C_{t s, h} \cdot \Delta h, E S_{-} C_{t s, h} \geq 0, \forall t s, h \\
E S_{-} E_{t s, h}=P S_{-} E_{t s, h} \cdot \Delta h, E S_{-} E_{t s, h} \geq 0, \forall t s, h \\
E S T_{h}=E S_{-} C_{h}-E S_{-} E_{h}, E S T_{h} \geq 0, \forall h
\end{array}
$$

Another constraint on the SoC has the purpose of avoiding any chance of overcoming its cap value $\left(\operatorname{SoC}_{-} \mathrm{Max}_{t s}\right)$ and its floor value $\left(\mathrm{SoC}_{-} \mathrm{Min}_{t s}\right)$. Consequently, for a better performance of the energy management of the ESS, a threshold SoC $\left(S_{0} C_{-} t h_{t s}\right)$ is introduced for each ESS to limit the values of $P S T_{t s, h}$. By using the binary variable Status $_{t s, h}$, the model can determine whether the SoC is above $S o C_{-} t h_{t s .}$. In this case, Status $t_{t s, h}$ turns to 1 and limits the value of $P S_{-} C_{t s, h}$ and $P S_{-} E_{t s, h}$, between more restrictive discharge $\left(P S_{-} E_{-} t h_{t s}\right)$ and charge $\left(P S_{-} C_{-} t h_{t s}\right)$ threshold 
This accepted manuscript does not include other publisher value-added contributions such as copyediting, formatting, technical enhancements and (if relevant) pagination.

limits. Otherwise, the charge and discharge limits are widened to $P S_{-} C_{-} M a x_{t s}$ and $P S_{-} E_{-} M a x_{t s}$, respectively.

$$
\begin{aligned}
& S o C_{t s, h} \leq S o C_{-} t h_{t s}+\operatorname{Statu}_{t s, h} \cdot\left(S_{o} C_{-} M a x_{t s}-S o C_{-} t h_{t s}\right) \\
& S o C_{t s, h} \geq S o C_{-} M_{i n}+\operatorname{Status}_{t s, h} \cdot\left(S_{t s} C_{-} t h_{t s}-S o C_{-} M i n_{t s}\right) \\
& P S_{-} C_{t s, h} \leq P S_{-} C_{-} t h_{t s}+\left(1-S t a t u s_{t s, h}\right) \cdot\left(P S_{-} C_{-} M a x_{t s}-P S_{-} C_{-} t h_{t s}\right) \\
& P S_{-} E_{t s, h} \leq P S_{-} E_{-} t h_{t s}+\left(1-S t a t u s_{t s, h}\right) \cdot\left(P S_{-} E_{-} M a x_{t s}-P S_{-} E_{-} t h_{t s}\right)
\end{aligned}
$$

d) Energy incomes and costs

The equations related to the grid energy cost (with and without self-consumption) are described according to the conceptual model proposed in [107] to simplify the model formulation:

a. Energy cost without self-consumption

Total_Energy_Cost $=A E_{-}$Grid $\cdot$ Energy_M1 + AP_Grid $\cdot$ Power_M $1+$ Energy_Cost

$$
\begin{array}{r}
\text { Energy_M } 1=\sum_{h} \text { Energy_M } 1_{h} \\
\text { Energy_Cost }=\sum_{h} \text { Energy_M } 1_{h} \cdot f e p p_{h}
\end{array}
$$

with Energy_M1, Energy_M1 $1_{h}$ and Power_M1 being the daily and hourly energy and the power related to the meter 1 in Fig. 4.

b. Energy cost with Type 1 self-consumption

Total_Energy_Cost_Self $=\left(A E_{-}\right.$Grid $+E_{-}$Charges $) \cdot$ Energy_M1 $+E_{-}$Charges . Energy_M2 $+\left(\right.$ AP_Grid $+P_{-} \_$Charges $) \cdot$ Power_M1 + P_Charges $\cdot$ Power_M $2+$ Energy_Cost 
This accepted manuscript does not include other publisher value-added contributions such as copy-

editing, formatting, technical enhancements and (if relevant) pagination.

with $E_{-}$Charges and $P_{-}$Charges being the energy and power charges defined by the RD 900/2015 according to the voltage level and type of self-consumption, and Energy_M2 and Power_M2 the daily energy and power related to the meter 2 in Fig. 4.

c. Income and cost with Type II self-consumption

In case of being under the Type II scheme, the owner of the facility would not only be considered a consumer but also a producer. As a producer, the owner would perceive an emolument (INC_Self) for the energy injected into the grid (eq. (23)), but at the same time, would undergo the costs $\left(I M P_{-} I N C, I M P_{-} E G E\right)$ arising from the charges and taxes applied to the producers by the Royal Decree-Law (RDL) 14/2010 [108] and the Law 15/2012 [109], respectively (eq. (24)):

$$
\begin{gathered}
I N C_{-} \text {Self }=\sum_{h} I N C_{-} S e l f_{h}=\sum_{h} E n e r g y_{-} M 1_{h} \cdot P m_{h} \\
I M P_{-} E X_{-} E=I M P_{-} I N C+I M P \_E G E
\end{gathered}
$$

e) Generation and storage cost

The daily generation $\left(C T_{-} E G T\right)$ and storage $\left(C T_{-} S t\right)$ total costs are the sums of their fixed $\left(C F_{-} G, C F_{-} S t\right)$ and variable $\left(C V_{-} G, C V_{-} S t\right)$ costs (Eqs. (25), (26)). In this regard, fixed costs are the product of the power rating of each RES and ESS of the facility and the values of the fixed cost parameters for each technology $\left(C F_{-} G_{t}\right.$ and $\left.C F_{-} S t_{t s}\right)$ (Eqs. (27), (28)). In the same way, the variable costs of each RES and ESS of the facility are a function of the energy delivered or consumed (Eqs. (29), (30)).

$$
\begin{aligned}
& C T_{-} E G T=C F_{-} G+C V_{-} G \\
& C T_{-} S t=C F_{-} S t+C V_{-} S t \\
& C F_{-} G=\sum_{t} C F_{-} G_{t} \cdot P G T_{t} \\
& C F_{-} S t=\sum_{t s} C F_{-} S t_{t s} \cdot P S T_{-} N_{t s}
\end{aligned}
$$




$$
\begin{gathered}
C V_{-} G=\sum_{t} \sum_{h} E G T_{t, h} \cdot C V_{-} G_{t} \\
C V_{-} S t=\sum_{t s} \sum_{h}\left\{\left(E S_{-} C_{t s, h}+E S_{-} E_{t s, h}\right) \cdot C V_{-} S t_{t s}\right\}
\end{gathered}
$$

f) Objective function

A new objective function is introduced, based on the Earnings Before Interest Taxes Depreciation and Amortization (EBITDA). It is addressed to optimise the savings of the system by minimising the difference between the EBITDA of the former model and the new EBITDA (EBITDA_Self) under the self-consumption scheme. This function is defined as follows:

$$
\text { O_function }=E B I T D A-E B I T D A \_S e l f
$$

Which for a Type I self-consumption scheme amounts to:

$$
\text { O_function=Total_Energy_Cost_Self }- \text { Total_Energy_Cost }
$$

And for a Type II self-consumption scheme:

$$
\text { O_function=Total_Energy_Cost_Self }+I M P_{-} E X_{-} E-I N C_{-} S e l f-T o t a l \_E n e r g y \_C o s t
$$

\subsection{Regarding the meters and the need of using a disjunctive program}

Both the energy cost and income present a disjunctive nature. That is, either the facility is consuming energy from the grid (in which case there will be an energy cost for the system and, consequently, no energy income at all) or it is injecting the surplus energy into the grid (in which case there will be an energy income but no energy cost). The same considerations apply to Meter 2.

In this regard, the disjunctive nature between energy cost and incomes equations and the measurements of the meters was solved by using a disjunctive program. A disjunctive program can be formulated as a special type of MINLP whose constraints can be defined using the 
This accepted manuscript does not include other publisher value-added contributions such as copyediting, formatting, technical enhancements and (if relevant) pagination.

logical "exclusive or" operator [110]. Concerning this, the big-M (BM) method was used to formulate the problem [111].

5. Case study: analysis of the impact of the RD 900/2015 Spanish self-consumption regulatory framework on the energy management of a low voltage microgrid

\subsection{Problem definition}

An actual consumer's low voltage facility with $P_{R}=5 \mathrm{~kW}$ was used to analyse the impact of the Spanish self-consumption regulatory framework on the energy management of a microgrid

(Figure 5). This microgrid is formed by a $2 \mathrm{~kW}$ PV system and an $8.9 \mathrm{~kW}$ ESS.

The operating costs of the PV system and the ESS are, 36.1€/kW/year [112] and $6.1 € / \mathrm{kW} /$ year and $0.49 € / \mathrm{MWh}$ [113], respectively. The other parameters related to the ESS, including the initial conditions of the ESS ts $\left(\mathrm{SoC}_{t s, 0}\right)$ can be found in Table 2.

$\begin{array}{cccccccc}P S_{-} C_{-} \text {Max }_{t s} & P S_{-} E_{-} \operatorname{Max}_{t s} & P S_{-} C_{-} t h_{t s} & P S_{-} E_{-} t h_{t s} & S_{0} C_{-} M a x_{t s} & S_{0} C_{-} M_{t s} & S_{0} C_{-} t h_{t s} & S_{0} C_{t s, 0} \\ {[W]} & {[W]} & {[W]} & {[W]} & & & & \\ 1000 & 1000 & 100 & 100 & 1 & 0.4 & 0.96 & 0.6\end{array}$

Table 2. Parameters related to the ESS model. 
This accepted manuscript does not include other publisher value-added contributions such as copy-

editing, formatting, technical enhancements and (if relevant) pagination.

The values of the access tariff cost and the self-consumption charges were provided by the several Spanish Ministerial Orders such as IET 107/2014 [114] and ETU 1976/2016 [115]. In Figure 5, the consumption of the system, the maximum capacity of generation and the energy prices are also depicted.
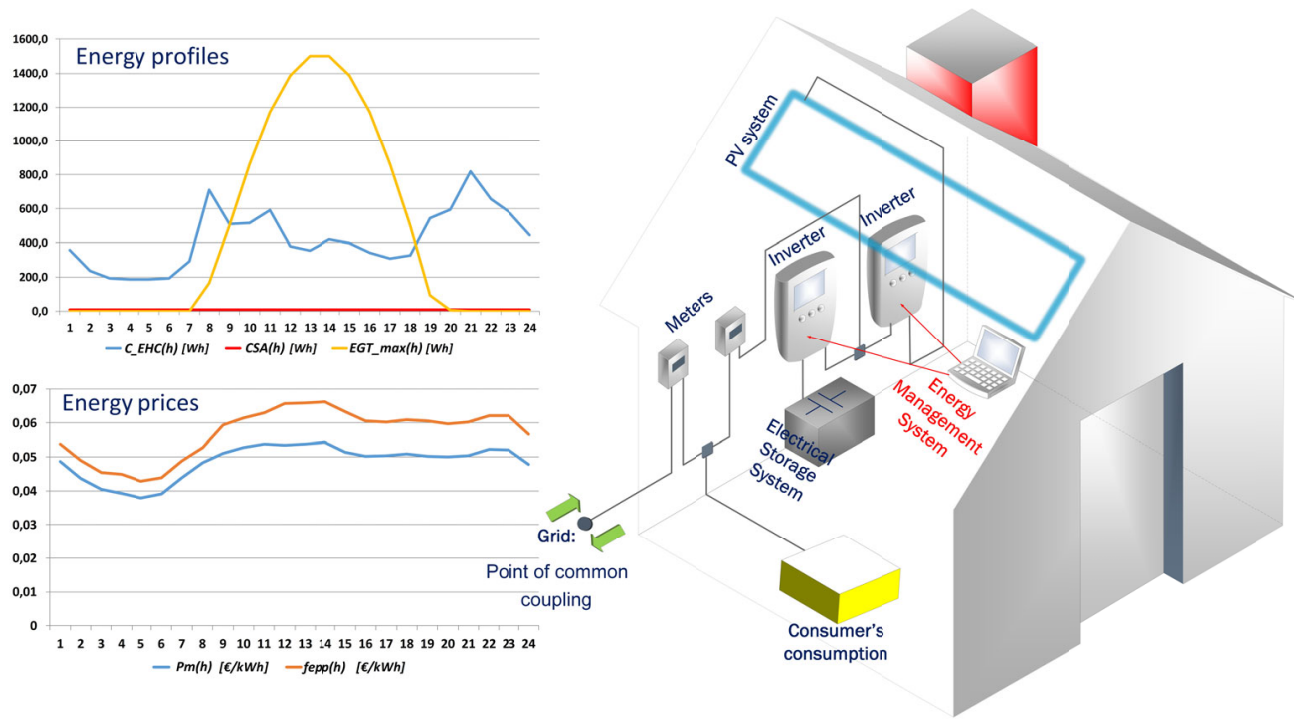

Figure 5. Conceptual approach to the problem description. Source: Self-elaboration.

The facility has an EMS that optimises the consumer's energy cost, which includes the required communication equipment for applying the set points to the DC/AC converters of the energy system. The employed model only states the optimal scheduling for one day and does not contemplate the optimal sizing of the power ratings of the facility components. The EMS is aimed to determine the energy plan of the microgrid, including production, storage and the energy exchange with the grid. This EMS has been operated considering the former model with self-consumption and the new model (Section 4) for both Types 1 and 2 of self-consumption.

This facility was emulated at the Microgrid Research Laboratory of Aalborg University [100] using hardware in the loop (HiL) architecture. As can be seen in Figure 6, this architecture has three levels: the software level, the real-time simulator level and the physical level. 
This accepted manuscript does not include other publisher value-added contributions such as copy-

editing, formatting, technical enhancements and (if relevant) pagination.

The software level was developed in the microgrid computer. There, using the developed models and the data storage, the EMS provided the scheduling to be applied to the system. The optimisation was achieved using the AIMMS Academic License [116] and its solver AIMMS Outer Approximation, as an Algebraic Modelling Language. In the same way, the software level was also in charge of the substation monitoring.

The real-time simulation level was performed on the platform dSPACE 1006, which includes the generation and consumption profiles, as well as a detailed model of a battery based energy storage system as proposed in [117]. This latter model allows reproducing the main dynamic and static characteristics of the battery variables such as voltage, current, and SoC. On top of that, the real-time level contains the controllers for the inverters implemented at the physical level, which are controlled as power sources or loads in accordance to generation or consumption profiles, presented in Figure 5, defined to emulate the behaviour of the renewable sources and the load, respectively. Meanwhile, the power references for the iniverters that interconnect the energy resources are defined by the upper control levels to guarantee compliance with the energy plan provided by the EMS. The details of the control level can be read in [60]. Although the dSPACE platform was running in real time, the time slot of the energy profiles and the scheduling were scaled down to $60 \mathrm{~s}$. As a result, the whole simulation lasts $1440 \mathrm{~s}$. Besides, the capacity of the ESS was also scaled in the same proportion [60].

Finally, the physical level is composed by the three inverters that emulate the PV system, the consumption, and the storage system which are interconnected to common AC bus through LCL filters, where a resistive load and the main grid are connected. The inverters are fed by a stiff regenerative DC source, which enables bidirectional power injections. The experimental setup was adapted to fit the electrical scheme imposed by the regulatory framework. The parameters of the microgrid are depicted in Table 3.

(c) <2019>. This manuscript version is made available under the CC-BY-NC-ND 4.0 

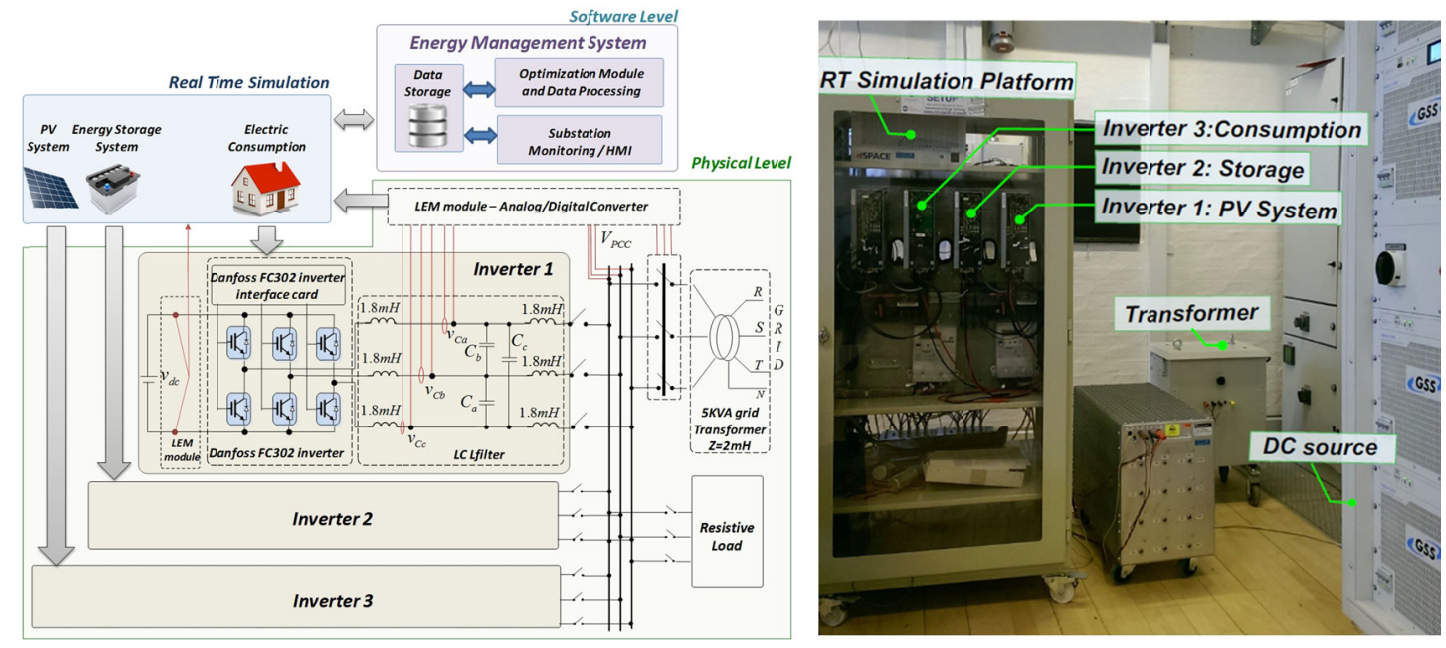

Figure 6. HiL implementation and experimental setup.

\begin{tabular}{|c|c|c|}
\hline Parameters & Symbol & Value \\
\hline & Power stage & \\
\hline Nominal Voltage & $E^{*}$ & $230 \cdot \sqrt{ } 2 \mathrm{~V}$ \\
\hline Nominal Frequency & $\omega^{*}$ & $2 \cdot \pi \cdot 50 \mathrm{rad} / \mathrm{s}$ \\
\hline Inverter inductors & L & $1.8 \mathrm{mH}$ \\
\hline Filter Capacitor & $\mathrm{C}$ & $27 \mu \mathrm{F}$ \\
\hline Nominal Load & C_EHC_N & $1000 \mathrm{~W}$ \\
\hline Maximum (RESs) and (ESSs) Power Rating & $P_{\max }$ & $1600 \mathrm{~W}$ \\
\hline Reactive power Reference & $Q^{*}$ & 0 VAR \\
\hline
\end{tabular}

(c) <2019>. This manuscript version is made available under the CC-BY-NC-ND 4.0 


\begin{tabular}{|lcc|}
\hline & Battery Array & \\
Nominal Voltage & & \\
Regulation Voltage & $\mathrm{V}_{\text {bat }}$ & $672 \mathrm{~V}$ \\
& & \\
Nominal Battery Capacity & $\mathrm{V}_{\mathrm{r}}$ & $756 \mathrm{~V}$ \\
& & \\
& $\mathrm{C}_{\text {bat }}$ & $16 \mathrm{Ah}$ \\
\hline
\end{tabular}

Table 3. Parameters of the microgrid

\subsection{Assessment of the results}

The results of both models applied to the facility under study are shown in Figures 7, 8 and 9. These figures are composed of six charts where different indicators of the facility are depicted. The charts belonging to the left side of the pictures illustrate the EMS scheduling results while those in the right side depict the experimental results of the EMS scheduling once applied on the setup. For each image, sections $a, b$ and $c$ represent, respectively, the inner relations between the consumption and generation line with the grid, the inner relationships in the generation power line and the performance of the ESS regarding its power and SoC.

Figure 7 shows the results of the EMS when the former model is applied. Specifically, Figure 7.a represents the aggregated consumption of the consumer, the energy provided or injected into the grid (meter 1) and the energy consumed or supplied by the generation power line (meter 2). There it can be seen that during the first hours of the day ( 3 am to 6 am) the EMS is focused on charging the ESS. In this regard, when looking at the charts 7.b and 7.c, it is possible to see that the energy consumption measured by meter 2 (positive value) is coincident with the ESS charge. At 7 am, once the ESS has been charged at a value close to $S o C_{-} t h_{t s}$, the energy provided by the grid to the facility becomes zero (see meter 1 ), and all the energy required by the consumer is provided either by the RES or by the ESS. Regarding the RES, 
from 7 am to 9 am it contributes along with the ESS to provide the necessary energy to guarantee the needs of the consumer. From $10 \mathrm{am}$ to $18 \mathrm{pm}$, the RES performs a vital role in the system as it is responsible for charging the ESS near to its threshold limits and providing the necessary energy to the consumer. After that, it is the ESS the maximum energy contributor, discharging at the end of the day to its initial condition. As a result, the use of the former model by the EMS allowed the facility to reduce its energy consumption from the grid up to $56 \%$.
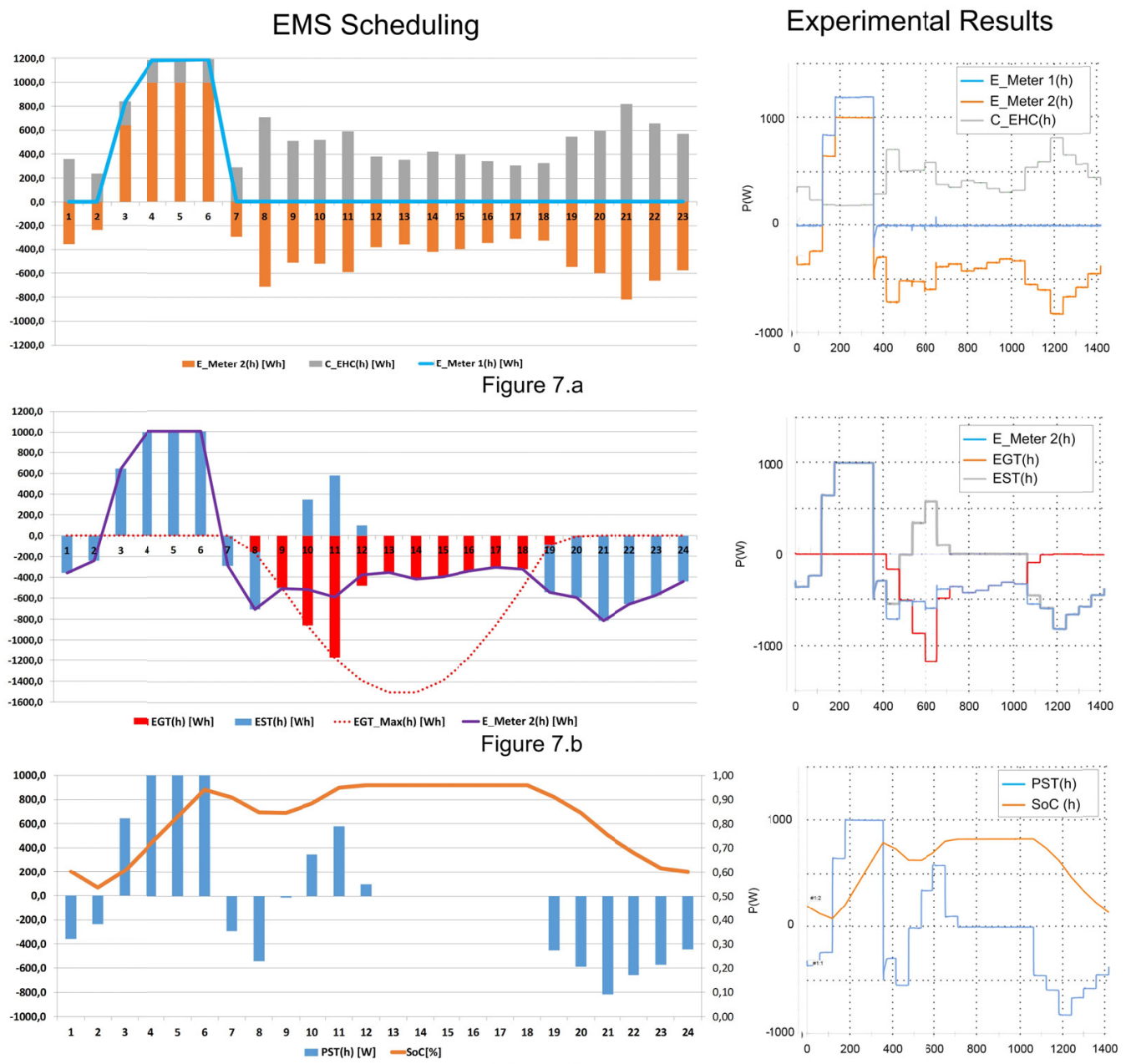

Figure 7.0

Figure 7. EMS solution applied to the facility under study according to

the former model and its experimental results. Source: Self-elaboration.

Next, Figures 8 and 9 provide the results of the EMS when the new model subjected to the Spanish self-consumption regulatory scheme is employed. In this regard, the regulatory 
This accepted manuscript does not include other publisher value-added contributions such as copy-

editing, formatting, technical enhancements and (if relevant) pagination.

constraints and the new objective function introduce a remarkable difference when managing the energy consumed or injected into the grid. As a result, for both Types I and II of selfconsumption (see Figure $8 . a$ and $9 . a$ ), just $5 \%$ of the energy consumption of the facility is provided by the grid, which is a non-despicable effect that highlights the importance to accurately define the regulatory constraints in models focused on managing this type of facilities.

The only slight difference between both types of self-consumption lies on the fact that, for self-consumption Type II, the total amount of energy injected into the grid during the day (2.2 $\mathrm{kWh})$ is greater than the energy injected under the Type I scheme (1.6kWh). As the injection of the energy to the grid is rewarded in Type II scheme, this difference seems perfectly reasonable. In this regard, when comparing Figures 8.a and 9.a, it is easy to see that this incentive forces the EMS to increase the injection of the energy when the energy market price is higher to increase the value of the incomes.

Regarding the energy management response in the self-consumption scheme, a resulting consequence of using the new model is that the elements belonging to the generation power line are forced to increase their participation in the energy supply (see Figures 8.b and 9.b) when comparing with the results of the former model (see Figure 7.b). In the case of the ESS under Type I and II regulatory scheme, the increase of energy supplied by the ESS if compared with the former model was about $8.3 \%$ and $20.9 \%$, respectively. Ergo, under both types of selfconsumption schemes, the ESS was compelled to reach its SoC limits (minimum and threshold) (see Figure 8.c and 9.c). Regarding the RES, this increase was even higher. For both types of regulatory schemes, the RES was forced to supply its maximum production of energy.

Concerning the experimental results, the set of figures have also demonstrated the excellent performance of the local controllers of the setup, which proved to be able to follow the scheduling provided by the EMS. 
EMS Scheduling

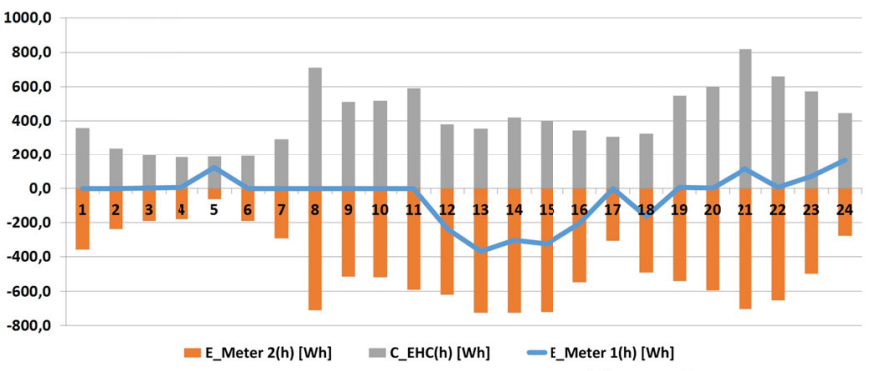

Figure 8.a

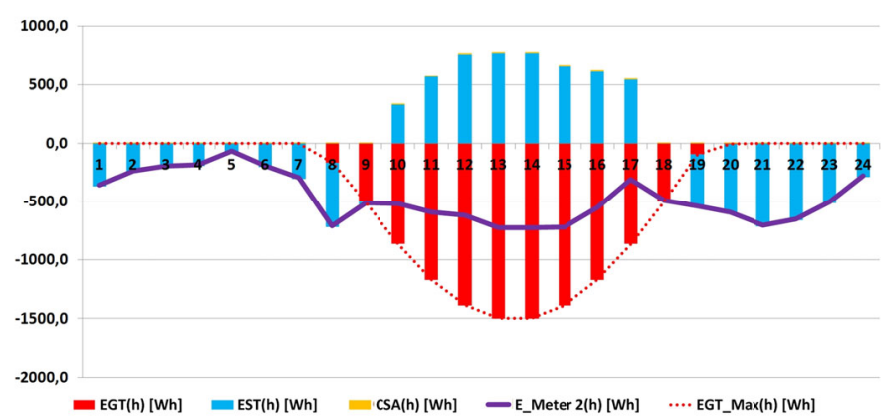

Figure 8.b

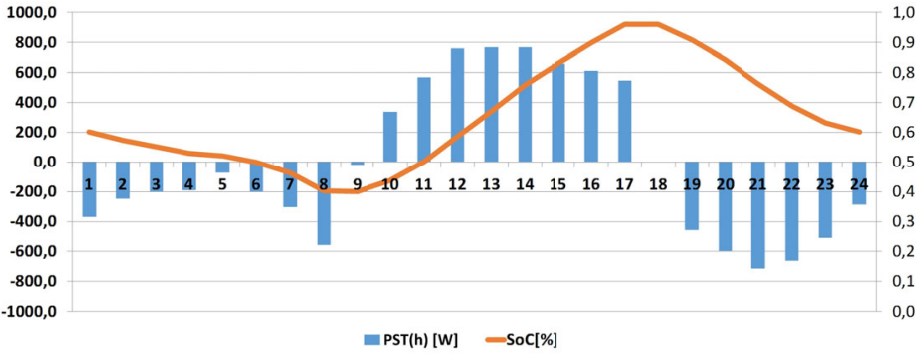

Figure 8.c
Experimental Results
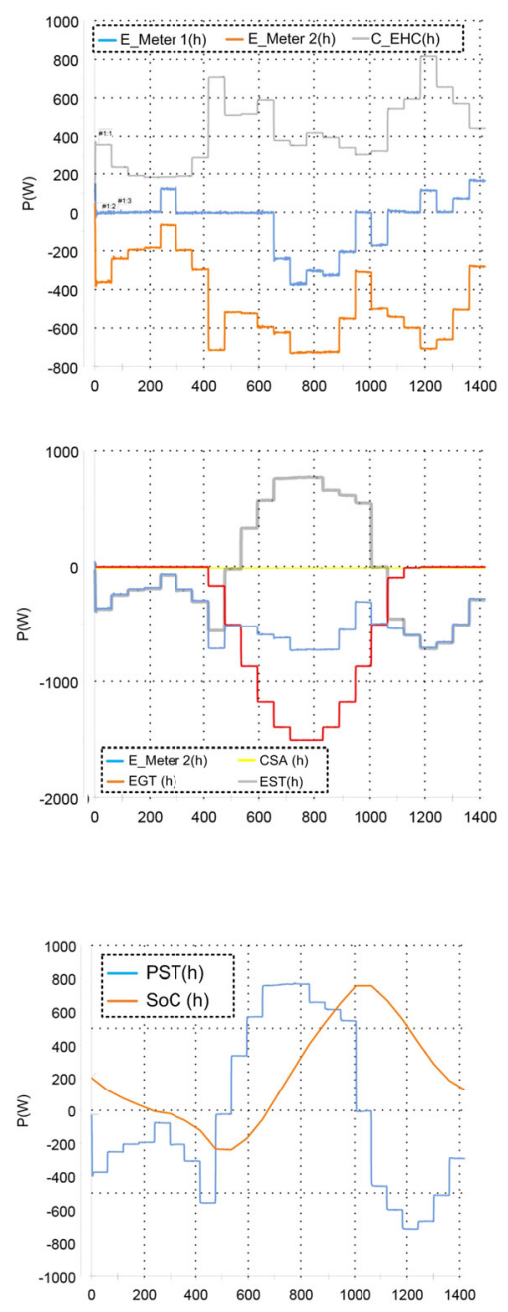

Figure 8. EMS solution applied to the facility under study according to the

Type I self-consumption scheme and its experimental results. Source: Self-elaboration. 
EMS Scheduling

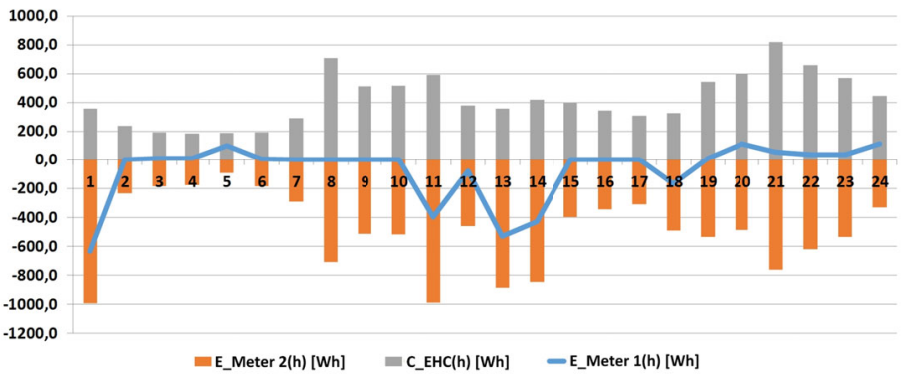

Figure 9.a

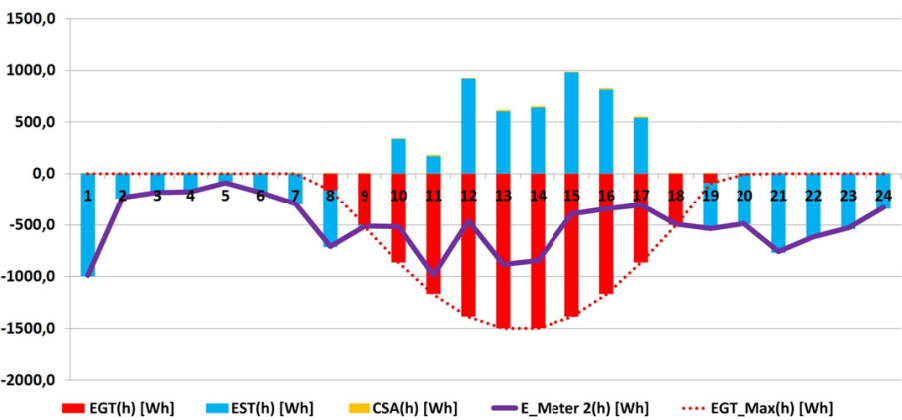

Figure 9.b

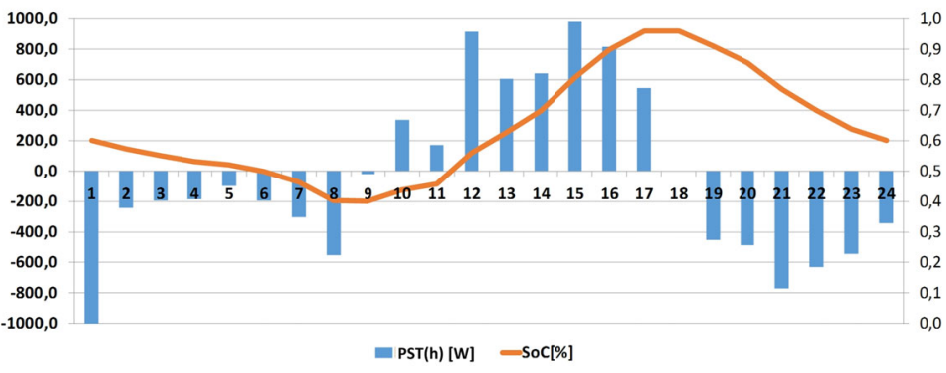

Figure 9.c
Experimental Results
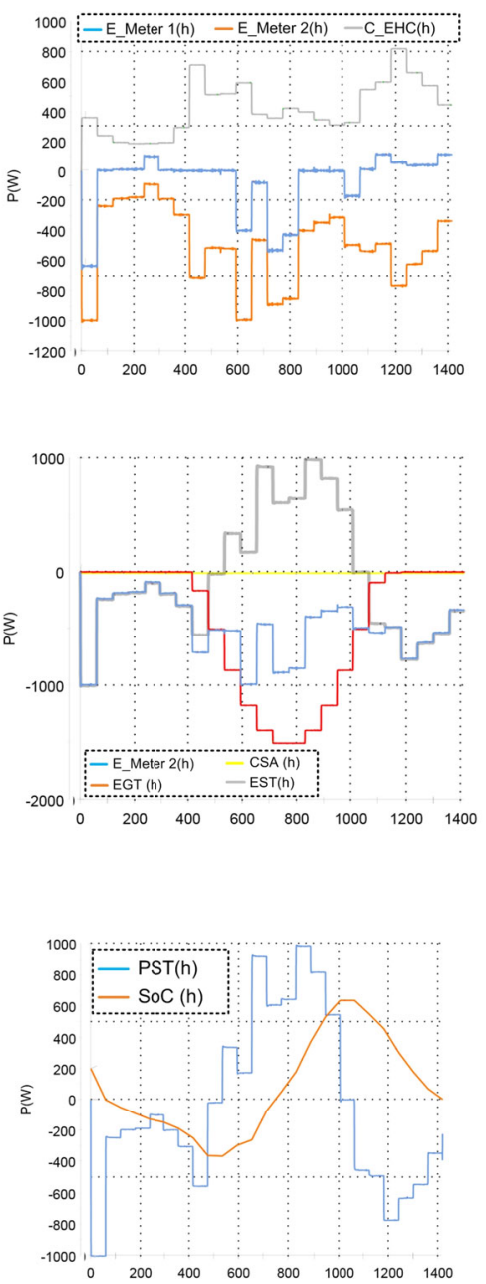

Figure 9. EMS solution applied to the facility under study according to the

Type II self-consumption scheme and its experimental results. Source: Self-elaboration.

\section{Conclusions}

A new model addressed to optimise the energy management of a low voltage microgrid has been developed. While most of all the existing models do not consider the regulatory restrictions applied to the facilities when optimising the energy management, the proposed new model contemplates in detail this type of constraints. 
This accepted manuscript does not include other publisher value-added contributions such as copyediting, formatting, technical enhancements and (if relevant) pagination.

A low voltage microgrid under the Spanish self-consumption scheme was selected as a case study and emulated at the Microgrid Research Laboratory of Aalborg University. The obtained results were analysed to determine whether the modelling of the regulatory scheme was relevant or not for the management of these types of facilities.

The results have corroborated the importance of considering the regulatory constraints when managing the facility, especially in relation to highly complex regulatory frameworks. Significant differences have appeared regarding the exchange of energy between the facility and the grid with and without taking into account the regulatory framework, such as a drastic reduction of the energy consumption provided by the grid and an increase of the use of the ESS and the RES of the system. These differences for the analysed case prove the weight that the regulatory constraints may have on the results of the optimisation process.

Microgrids are called to be handy tools for the deployment of renewable energy systems, especially on buildings and industry. In this regard, the results also corroborate that those microgrid manufacturers interested in differentiating themselves from competitors might see the energetic and economic performance of their products increased by embedding these regulatory constraints in their EMS. In this regard, the Regulatory-Framework-Embedded energy management system approach could be a useful tool to improve the optimal use of microgrids.

\section{Acknowledgements:}

This work has been partially supported by the research project ENE2015-64087-C2-1-R (MINECO/FEDER). We would like to thank AIMMS B.V. for providing us with the Academic License of the software AIMMS 
This accepted manuscript does not include other publisher value-added contributions such as copy-

editing, formatting, technical enhancements and (if relevant) pagination.

\section{References}

[1] REN21. Renewables 2018. Global status report. 2018.: http://www.ren21.net/wpcontent/uploads/2018/06/17-8652_GSR2018_FullReport_web_final_.pdf. Last access online, August 2018

[2] Palizban O, Kauhaniemi K, Guerrero JM. Microgrids in active network management—Part I: Hierarchical control, energy storage, virtual power plants, and market participation. Renewable and Sustainable Energy Reviews, Volume 36, August 2014, Pages 428-439

[3] Naz MN, Mushtaq MI, Naeem M, Iqbal M, Altaf MW, Haneef M. Multicriteria decision making for resource management in renewable energy assisted microgrids. Renewablle and Sustainable Energy Reviews, Volume 71, May 2017, Pages 323-341

[4] Zia MF, Elbouchikhi E, Benbouzid M. Microgrids energy management systems: A critical review on methods, solutions, and prospects. Applied Energy, Volume 222, July 2018, Pages 1033-1055

[5] Liu T, Tan X, Sun B, Wu Y, Tsang DHK. Energy management of cooperative microgrids: A distributed optimization approach. International Journal of Electrical Power \& Energy Systems, Volume 96, March 2018, Pages 335-346

[6] Ghasemi A. Coordination of pumped-storage unit and irrigation system with intermittent wind generation for intelligent energy management of an agricultural microgrid. Energy, Volume 142, 1 January 2018, Pages 1-13

[7] Silvente J, Papageorgiou LG. An MILP formulation for the optimal management of microgrids with task interruptions. Applied Energy, Volume 206, 15 November 2017, Pages 1131-1146

[8] Jin X, Wu J, Mu Y, Wang M, Xu X, Jia H. Hierarchical microgrid energy management in an office building. Applied Energy, Volume 208, 15 December 2017, Pages 480-494 
This accepted manuscript does not include other publisher value-added contributions such as copyediting, formatting, technical enhancements and (if relevant) pagination.

[9] Sarshar J, Moosapour SS, Joorabian M. Multi-objective energy management of a micro-grid considering uncertainty in wind power forecasting. Energy, Volume 139, 15 November 2017, Pages 680-693

[10] Anvari-Moghaddam A, Rahimi-Kian A, Mirian MS, Guerrero JM. A multi-agent based energy management solution for integrated buildings and microgrid system. Applied Energy, Volume 203, 1 October 2017, Pages 41-56

[11] Bendato I, Bonfiglio A, Brignone M, Delfino F, Pampararo F, Procopio R. Definition and onfield validation of a microgrid energy management system to manage load and renewable uncertainties and system operator requirements. Electric Power Systems Research, Volume 146, May 2017, Pages 349-361

[12] Kou P, Liang D, Gao L. Distributed EMPC of multiple microgrids for coordinated stochastic energy management. Applied Energy, Volume 185, Part 1, 1 January 2017, Pages 939-952

[13] Aghajani GR, Shayanfar HA, ShayeghiH. Demand side management in a smart micro-grid in the presence of renewable generation and demand response. Energy, Volume 126, 1 May 2017, Pages 622-637

[14] Tabar VS, Jirdehi MA, Hemmati R. Energy management in microgrid based on the multi objective stochastic programming incorporating portable renewable energy resource as demand response option. Energy, Volume 118, 1 January 2017, Pages 827-839

[15] Elsied M, Oukaour A, Youssef T, Gualous H, Mohammed O. An advanced real time energy management system for microgrids. Energy, Volume 114, 1 November 2016, Pages 742-752

[16] Tabatabaee S, Mortazavi SS, Niknam T. Stochastic energy management of renewable micro-grids in the correlated environment using unscented transformation. Energy, Volume 109, 15 August 2016, Pages 365-377

(C) $<2019>$. This manuscript version is made available under the CC-BY-NC-ND 4.0 
This accepted manuscript does not include other publisher value-added contributions such as copyediting, formatting, technical enhancements and (if relevant) pagination.

[17] Hu MC, Lu SY, Chen YH. Stochastic programming and market equilibrium analysis of microgrids energy management systems. Energy, Volume 113, 15 October 2016, Pages 662670

[18] ChenY, Hu M. Balancing collective and individual interests in transactive energy management of interconnected micro-grid clusters. Energy, Volume 109, 15 August 2016, Pages 1075-1085

[19] Deihimi A, Zahed BK, Iravani R. An interactive operation management of a micro-grid with multiple distributed generations using multi-objective uniform water cycle algorithm. Energy, Volume 106, 1 July 2016, Pages 482-509

[20] Abedini M, Moradi MH, Hosseinian SM. Optimal management of microgrids including renewable energy scources using GPSO-GM algorithm. Renewable Energy, Volume 90, May 2016, Pages 430-439

[21] Petrollese M, Valverde L, Cocco D, Cau G, Guerra J. Real-time integration of optimal generation scheduling with MPC for the energy management of a renewable hydrogen-based microgrid. Applied Energy, Volume 166, 15 March 2016, Pages 96-106

[22] Basir Khan MR, Jidin R, Pasupuleti J. Multi-agent based distributed control architecture for microgrid energy management and optimization. Energy Conversion and Management, Volume 112, 15 March 2016, Pages 288-307

[23] Najibi F, Niknam T, Kavousi-Fard A. Optimal stochastic management of renewable MG (micro-grids) considering electro-thermal model of PV (photovoltaic). Energy, Volume 97, 15 February 2016, Pages 444-459

[24] Tianguang Lv, Qian Ai. Interactive energy management of networked microgrids-based active distribution system considering large-scale integration of renewable energy resources. Applied Energy, Volume 163, 1 February 2016, Pages 408-422 
This accepted manuscript does not include other publisher value-added contributions such as copyediting, formatting, technical enhancements and (if relevant) pagination.

[25] Jabbari-Sabet R, Moghaddas-Tafreshi SM, Mirhoseini SS. Microgrid operation and management using probabilistic reconfiguration and unit commitment. International Journal of Electrical Power \& Energy Systems, Volume 75, February 2016, Pages 328-336

[26] Mohan V, Singh JG, Ongsakul W. An efficient two stage stochastic optimal energy and reserve management in a microgrid. Applied Energy, Volume 160, 15 December 2015, Pages 28-38

[27] Aghajani GR, Shayanfar HA, Shayeghi H. Presenting a multi-objective generation scheduling model for pricing demand response rate in micro-grid energy management. Energy Conversion and Management, Volume 106, December 2015, Pages 308-321

[28] Pascual J, Barricarte J, Sanchis P, Marroyo L. Energy management strategy for a renewable-based residential microgrid with generation and demand forecasting. Applied Energy, Volume 158, 15 November 2015, Pages 12-25

[29] Safamehr H, Rahimi-Kian A. A cost-efficient and reliable energy management of a microgrid using intelligent demand-response program. Energy, Volume 91, November 2015, Pages 283-293

[30] Karavas CS, Kyriakarakos G, Arvanitis KG, Papadakis G. A multi-agent decentralized energy management system based on distributed intelligence for the design and control of autonomous polygeneration microgrids. Energy Conversion and Management, Volume 103, October 2015, Pages 166-179

[31] Mazzola S, Astolfi M, Macchi E. A detailed model for the optimal management of a multigood microgrid. Applied Energy, Volume 154, 15 September 2015, Pages 862-873

[32] Korkas CD, Baldi S, Michailidis I, Kosmatopoulos EB. Intelligent energy and thermal comfort management in grid-connected microgrids with heterogeneous occupancy schedule. Applied Energy, Volume 149, 1 July 2015, Pages 194-203 
This accepted manuscript does not include other publisher value-added contributions such as copyediting, formatting, technical enhancements and (if relevant) pagination.

[33] Silvente J, Aguirre AM, Zamarripa MA, Méndez CA, Graells M, Espuña A. Improved time representation model for the simultaneous energy supply and demand management in microgrids. Energy, Volume 87, 1 July 2015, Pages 615-627

[34] Xu X, Jia H, Wang D, Yu DC, Chiang HD. Hierarchical energy management system for multi-source multi-product microgrids. Renewable Energy, Volume 78, June 2015, Pages 621630

[35] Tenfen D, Finardi EC. A mixed integer linear programming model for the energy management problem of microgrids. Electric Power Systems Research, Volume 122, May 2015, Pages 19-28

[36] Elsied M, Oukaour A, Gualous H, Hassan R. Energy management and optimization in microgrid system based on green energy. Energy, Volume 84, 1 May 2015, Pages 139-151

[37] Alavi SA, Ahmadian A, Aliakbar-Golkar M. Optimal probabilistic energy management in a typical micro-grid based-on robust optimization and point estimate method. Energy Conversion and Management, Volume 95, 1 May 2015, Pages 314-325

[38] Comodi G, Giantomassi A, Severini M, Squartini S, Ferracuti F, Fonti A, Cesarini DN, Morodo M, Polonara F. Multi-apartment residential microgrid with electrical and thermal storage devices: Experimental analysis and simulation of energy management strategies. Applied Energy, Volume 137, 1 January 2015, Pages 854-866

[39] Kuznetsova E, Ruiz C, Yan-Fu Li, Zio E. Analysis of robust optimization for decentralized microgrid energy management under uncertainty. International Journal of Electrical Power \& Energy Systems, Volume 64, January 2015, Pages 815-832

[40] Ji L, Niu DX, Xu M, Huang GH. An optimization model for regional micro-grid system management based on hybrid inexact stochastic-fuzzy chance-constrained programming. International Journal of Electrical Power \& Energy Systems, Volume 64, January 2015, Pages $1025-1039$

(c) <2019>. This manuscript version is made available under the CC-BY-NC-ND 4.0 
This accepted manuscript does not include other publisher value-added contributions such as copyediting, formatting, technical enhancements and (if relevant) pagination.

[41] Prodan I, Zio E. A model predictive control framework for reliable microgrid energy management. International Journal of Electrical Power \& Energy Systems, Volume 61, October 2014, Pages 399-409

[42] Cau G, Cocco D, Petrollese M, Kær SK, Milan C. Energy management strategy based on short-term generation scheduling for a renewable microgrid using a hydrogen storage system. Energy Conversion and Management, Volume 87, November 2014, Pages 820-831

[43] Ji L, Niu DX, Huang GH. An inexact two-stage stochastic robust programming for residential micro-grid management-based on random demand. Energy, Volume 67, 1 April 2014, Pages 186-199

[44] Motevasel M, Seifi AR. Expert energy management of a micro-grid considering wind energy uncertainty. Energy Conversion and Management, Volume 83, July 2014, Pages 58-72

[45] Mohammadi S, Soleymani S, Mozafari B. Scenario-based stochastic operation management of MicroGrid including Wind, Photovoltaic, Micro-Turbine, Fuel Ciell and Energy Storage Devices. International Journal of Electrical Power \& Energy Systems, Volume 54, January 2014, Pages 525-535

[46] Wang R, Wang P, Xiao G, Gong S. Power demand and supply management in microgrids with uncertainties of renewable energies. International Journal of Electrical Power \& Energy Systems, Volume 63, December 2014, Pages 260-269

[47] Kuznetsova E, Li YF, Ruiz C, Zio E. An integrated framework of agent-based modelling and robust optimization for microgrid energy management. Applied Energy, Volume 129, 15 September 2014, Pages 70-88

[48] Velik R, Nicolay P. A cognitive decision agent architecture for optimal energy management of microgrids. Energy Conversion and Management, Volume 86, October 2014, Pages 831-847 
This accepted manuscript does not include other publisher value-added contributions such as copyediting, formatting, technical enhancements and (if relevant) pagination.

[49] Baziar A, Kavousi-Fard A. Considering uncertainty in the optimal energy management of renewable micro-grids including storage devices. Renewable Energy, Volume 59, November 2013, Pages 158-166

[50] Zhang D, Shah N, Papageorgiou LG. Efficient energy consumption and operation management in a smart building with microgrid. Energy Conversion and Management, Volume 74, October 2013, Pages 209-222

[51] Niknam T, Golestaneh F, Shafiei M. Probabilistic energy management of a renewable microgrid with hydrogen storage using self-adaptive charge search algorithm. Energy, Volume 49, 1 January 2013, Pages 252-267

[52] López MA, Martín S, Aguado JA, de la Torre S. V2G strategies for congestion management in microgrids with high penetration of electric vehicles. Electric Power Systems Research, Volume 104, November 2013, Pages 28-34

[53] Motevasel M, Seifi AR, Niknam T. Multi-objective energy management of CHP (combined heat and power)-based micro-grid. Energy, Volume 51, 1 March 2013, Pages 123-136

[54] Alvarez E, Campos AM, Arboleya P, Gutiérrez AJ. Microgrid management with a quick response optimization algorithm for active power dispatch. International Journal of Electrical Power \& Energy Systems, Volume 43, Issue 1, December 2012, Pages 465-473

[55] Niknam T, Golestaneh F, Malekpour A. Probabilistic energy and operation management of a microgrid containing wind/photovoltaic/fuel cell generation and energy storage devices based on point estimate method and self-adaptive gravitational search algorithm. Energy, Volume 43, Issue 1, July 2012, Pages 427-437

[56] Mohamed FA, Koivo HN. Online management genetic algorithms of microgrid for residential application. Energy Conversion and Management, Volume 64, December 2012, Pages 562-568 
This accepted manuscript does not include other publisher value-added contributions such as copy-

editing, formatting, technical enhancements and (if relevant) pagination.

[57] Mohamed FA, Koivo HN. Multiobjective optimization using Mesh Adaptive Direct Search for power dispatch problem of microgrid. International Journal of Electrical Power \& Energy Systems, Volume 42, Issue 1, November 2012, Pages 728-735

[58] Mohamed FA, Koivo HN. System modelling and online optimal management of MicroGrid using Mesh Adaptive Direct Search. International Journal of Electrical Power \& Energy Systems, Volume 32, Issue 5, June 2010, Pages 398-407

[59] Luna AC, Meng L, Diaz NL, Graells M, Vasquez JC, Guerrero JM. Online Energy Management Systems for Microgrids: Experimental Validation and Assessment Framework. IEEE Transactions on Power Electronics, Volume 33, Issue 3, 2018, Pages 2201 - 2215

[60] Luna AC, Diaz NL, Graells M, Vasquez JC, Guerrero JM. Mixed-Integer-LinearProgramming-Based Energy Management System for Hybrid PV-Wind-Battery Microgrids: Modeling, Design, and Experimental Verification. IEEE Transactions on Power Electronics, Volume 32, Issue 4, 2017, Pages $2769-2783$

[61] Li M, Zhang X, Li G, Jiang C. A feasibility study of microgrids for reducing energy use and GHG emissions in an industrial application. Applied Energy 2016;176:138-48.

[62] Amrollahi MH, Bathaee SMT. Techno-economic optimization of hybrid photovoltaic/wind generation together with energy storage system in a stand-alone micro-grid subjected to demand response. Applied Energy 2017;202:66-77.

[63] Caballero F, Sauma E, Yanine F. Business optimal design of a grid-connected hybrid PV (photovoltaic)-wind energy system without energy storage for an Easter Island's block. Energy 2013;61:248-61.

[64] Li FF, Qiu J. Multi-objective optimization for integrated hydrophotovoltaic power system. Applied Energy 2016;167:377-84.

[65] Sukumar S, Mokhlis H, Mekhilef S, Naidu K, Karimi M. Mix-mode energy management strategy and battery sizing for economic operation of grid-tied microgrid. Energy 2017;118:1322-33. 
This accepted manuscript does not include other publisher value-added contributions such as copy-

editing, formatting, technical enhancements and (if relevant) pagination.

[66] Almada J, Leão R, Sampaio R, Barroso G. A centralized and heuristic approach for energy management of an ac microgrid. Renew Sustain Energy Reviews 2016;60:1396-404.

[67] Fossati JP, Galarza A, Martín-Villate A, Echeverría JM, Fontán L. Optimal scheduling of a microgrid with a fuzzy logic controlled storage system. Int J Electr Power Energy Syst 2015;68:61-70.

[68] Moghaddam AA, Seifi A, Niknam T, Pahlavani MRA. Multi-objective operation management of a renewable $\mathrm{mg}$ (micro-grid) with back-up micro-turbine/fuel cell/battery hybrid power source. Energy 2011;36(11):6490-507.

[69] Rezaei N, Kalantar M. Stochastic frequency-security constrained energy and reserve management of an inverter interfaced islanded microgrid considering demand response programs. Int J Electr Power Energy Syst 2015;69:273-86.

[70] Wang C, Liu Y, Li X, Guo L, Qiao L, Lu H. Energy management system for standalone diesel-wind-biomass microgrid with energy storage system. Energy 2016;97:90-104.

[71] Javidsharifi M, Niknam T, Aghaei J, Mokryani G. Multi-objective short-term scheduling of a renewable-based microgrid in the presence of tidal resources and storage devices. Applied Energy 2018;216:367-81.

[72] Vergara PP, López JC, da Silva LC, Rider MJ. Security-constrained optimal energy management system for three-phase residential microgrids. Electr Power Syst Res 2017;146:371-82.

[73] Choudar A, Boukhetala D, Barkat S, Brucker J-M. A local energy management of a hybrid PV-storage based distributed generation for microgrids. Energy Convers Manage 2015;90:2133.

[74] Sechilariu M, Wang B, Locment F. Building-integrated microgrid: advanced local energy management for forthcoming smart power grid communication. Energy Build 2:013;59:236-43.

[75] Chalise S, Sternhagen J, Hansen TM, Tonkoski R. Energy management of remote microgrids considering battery lifetime. Electr J 2016;29(6):1-10.

[76] Marzband M, Yousefnejad E, Sumper A, Domínguez-García JL. Real time experimental implementation of optimum energy management system in standalone microgrid by using multilayer ant colony optimization. Int J Electr Power Energy Syst 2016;75:265-74. 
This accepted manuscript does not include other publisher value-added contributions such as copy-

editing, formatting, technical enhancements and (if relevant) pagination.

[77] Marzband M, Ghadimi M, Sumper A, Domínguez-García JL. Experimental validation of a real-time energy management system using multi-period gravitational search algorithm for microgrids in islanded mode. Applied Energy 2014;128:164-74.

[78] Motevasel M, Seifi AR. Expert energy management of a micro-grid considering wind energy uncertainty. Energy Convers Manage 2014;83:58-72.

[79] Marzband M, Ghazimirsaeid SS, Uppal H, Fernando T. A real-time evaluation of energy management systems for smart hybrid home microgrids. Electr Power Syst Res 2017;143:62433.

[80] Velik R, Nicolay P. Grid-price-dependent energy management in microgrids using a modified simulated annealing triple-optimizer. Applied Energy 2014;130:384-95.

[81] Arcos-Aviles D, Pascual J, Guinjoan F, Marroyo L, Sanchis P, Marietta MP. Low complexity energy management strategy for grid profile smoothing of a residential grid-connected microgrid using generation and demand forecasting. Applied Energy 2017;205:69-84.

[82] Kyriakarakos G, Dounis Al, Arvanitis KG, Papadakis G. A fuzzy logic energy management system for polygeneration microgrids. Renewable Energy 2012;41:315-27.

[83] De Santis E, Rizzi A, Sadeghian A. Hierarchical genetic optimization of a fuzzy logic system for energy flows management in microgrids. Appl Soft Comput 2017;60:135-49.

[84] Kuznetsova E, Li Y-F, Ruiz C, Zio E, Ault G, Bell K. Reinforcement learning for microgrid energy management. Energy 2013;59:133-46.

[85] Mendes PR, Isorna LV, Bordons C, Normey-Rico JE. Energy management of an experimental microgrid coupled to a V2G system. J Power Sources 2016;327:702-13.

[86] Luo Z, Wu Z, Li Z, Cai H, Li B, Gu W. A two-stage optimization and control for CCHP microgrid energy management. Appl Therm Eng 2017;125:513-22.

[87] Prodan I, Zio E, Stoican F. Fault tolerant predictive control design for reliable microgrid energy management under uncertainties. Energy 2015;91:20-34.

[88] Lo Prete C, Hobbs BF. A cooperative game theoretic analysis of incentives for microgrids in regulated electricity markets. Applied Energy, Volume 169, May 2016, Pages 524-541 
This accepted manuscript does not include other publisher value-added contributions such as copy-

editing, formatting, technical enhancements and (if relevant) pagination.

[89] Kia M, Nazar MS, Sepasian MS, Heidari A, Siano P. An efficient linear model for optimal day ahead scheduling of CHP units in active distribution networks considering load commitment programs. Energy, Volume 139, November 2017, Pages 798-817

[90] Holjevac N, Capuder T, Zhang N, Kuzle I, Kang C. Corrective receding horizon scheduling of flexible distributed multi-energy microgrids. Applied Energy, Volume 207, December 2017, Pages 176-194

[91]Ramos-Teodoro J, Rodríguez F, Berenguel M, Torres JL. Heterogeneous resource management in energy hubs with self-consumption: Contributions and application example. Applied Energy, Volume 229, November 2018, Pages 537-550

[92] Sreedharan P, Farbes J, Cutter E, Woo CK, Wang J. Microgrid and renewable generation integration: University of California, San Diego. Applied Energy, Volume 169, May 2016, Pages 709-720

[93] Olivella-Rosell $P$, Bullich-Massagué E, Aragüés-Peñalba M, Sumper A, Ødegaard Ottesen S, Vidal-Clos J A, Villafáfila-Robles R. Optimization problem for meeting distribution system operator requests in local flexibility markets with distributed energy resources. Applied Energy, Volume 210, January 2018, Pages 881-895

[94] Nguyen S, Peng W, Sokolowski P, Alahakoon D, Yu X. Optimizing rooftop photovoltaic distributed generation with battery storage for peer-to-peer energy trading. Applied Energy, Volume 228, October 2018, Pages 2567-2580

[95] Long C, Wu J, Zhou Y, Jenkins N. Peer-to-peer energy sharing through a two-stage aggregated battery control in a community Microgrid. Applied Energy, Volume 226, September 2018, Pages 261-276

[96] Zhang C, Wu J, Zhou Y, Cheng M, Long C. Peer-to-Peer energy trading in a Microgrid. Applied Energy, Volume 220, June 2018, Pages 1-12

[97] Scheller F, Burgenmeister B, Kondziella H, Kühne S, Reichelt DG, Bruckner T. Towards integrated multi-modal municipal energy systems: An actor-oriented optimization approach. Applied Energy, Volume 228, October 2018, Pages 2009-2023

[98] de la Hoz J, Martín H, Miret, J, Castilla M, Guzman R. Evaluating the 2014 retroactive regulatory framework applied to the grid connected PV systems in Spain. Applied Energy, Volume 170, 15 May 2016, Pages 329-344. 
This accepted manuscript does not include other publisher value-added contributions such as copyediting, formatting, technical enhancements and (if relevant) pagination.

[99] de la Hoz J, Martín H, Montalà M, Matas J, Guzman R. Assessing the 2014 retroactive regulatory framework applied to the concentrating solar power systems in Spain. Applied Energy, Volume 212, 15 February 2018, Pages 1377-1399

[100] Meng L Luna A, Rodríguez Díaz E, Sun B, Dragicevic T, Savaghebi M, Vasquez JC, Guerrero JM, Graells M, Andrade F. Flexible System Integration and Advanced Hierarchical Control Architectures in the Microgrid Research Laboratory of Aalborg University. IEEE Transactions on Industry Applications, Volume 52, Issue 2, 2016, Pages 1736 - 1749

[101] RD 216/2014, of 28 March. BOE no. 77, March 29, 2014.

https://www.boe.es/diario_boe/txt.php?id=BOE-A-2014-3376. Last access online, August 2018

[102] RD 2019/1997, of 26 December. BOE no. 310, December 27, 1997.

https://boe.es/buscar/act.php?id=BOE-A-1997-27817. Last access online, August 2018

[103] Resolution of May 9, 2018, of the Secretary of State for Energy. BOE no. 115, May 11, 2018. https://www.boe.es/buscar/pdf/2018/BOE-A-2018-6295-consolidado.pdf. Last access online, August 2018

[104] Law 24/2013, of 26 December. BOE no. 167, December 27, 2013. http://www. boe.es/diario_boe/txt.php?id=BOE-A-2013-13645. Last access online, August 2018

[105] RD 1164/2001, of 26 October. BOE no. 268, November 8, 2001.

https://www.boe.es/buscar/doc.php?id=BOE-A-2001-20850. Last access online, August 2018

[106] RD 900/2015, of 9 October. BOE no. 243, October 10, 2015.

https://www.boe.es/diario_boe/txt.php?id=BOE-A-2015-10927. Last access online, August 2018

[107] Aragonés V, Barquín J, Alba J. The New Spanish Self-consumption Regulation. Energy Procedia, Volume 106, December 2016, Pages 245-257

[108] RDL 14/2010, of 23 December. BOE no. 312, December 24, 2010.

https://www.boe.es/buscar/doc.php?id=BOE-A-2010-19757. Last access online, August 2018

(c) <2019>. This manuscript version is made available under the CC-BY-NC-ND 4.0 
This accepted manuscript does not include other publisher value-added contributions such as copyediting, formatting, technical enhancements and (if relevant) pagination.

[109] Law 15/2012, of 27 December. BOE no. 312, December 28, 2012. https://www.boe.es/buscar/doc.php?id=BOE-A-2012-15649. Last access online, August 2018

[110] Edgar TF, Himmelblau DM. Optimization of Chemical Processes. McGraw-Hill Science/Engineering/Math; 2 edition (January 12, 2001). ISBN-10: 0070393591. ISBN-13: 9780070393592

[111] Trespalacios F, Grossman IE. Review of Mixed-Integer Nonlinear and Generalized Disjunctive Programming Methods. Chemie Ingenieur Techink 2014. 86, №7, 991-1012. https://doi.org/10.1002/cite.201400037

[112] Plan de Energías Renovables 2011-2020. Ministerio de Industria, Turismo y comercio. Instituto para la Diversificación y ahorro de la Energía. IDAE. November 2011. http://www.idae.es/tecnologias/energias-renovables/plan-de-energias-renovables-2011-2020. In Spanish. Last access on line, August 2018

[113] Zakeri B, Syri S. Electrical energy storage systems: A comparative life cycle cost analysis. Renewable and Sustainable Energy Reviews. Volume 42, February 2015, Pages 569-596

[114] Order IET/107/2014, of 31 January. BOE no. 28, February 1, 2014.

https://www.boe.es/diario boe/txt.php?id=BOE-A-2014-1052. Last access online, August 2018

[115] Order ETU/1976/2016, of 23 December. BOE no. 314, December 29, 2016.

https://www.boe.es/diario boe/txt.php?id=BOE-A-2016-12464. Last access online, August 2018

[116] AIMMS B.V., version 1.0.0.19, Haarlem, The Netherlands, 2016

[117] T. Kim and W. Qiao, A Hybrid Battery Model Capable of Capturing Dynamic Circuit Characteristics and Nonlinear Capacity Effects, in IEEE Transactions on Energy Conversion, vol. 26, no. 4, pp. 1172-1180, December 2011.

(c) <2019>. This manuscript version is made available under the CC-BY-NC-ND 4.0 


\section{Acronyms}

DER: Distributed Energy Resources

EBITDA: Earnings Before Interest Taxes Depreciation and Amortization

EMS: Energy Management System

ESS: Energy Storage System

EU: European Union

HiL: hardware in the loop

IEM: the Iberian Electricity Market

LSES: Law of the Spanish Electricity Sector

MINLP: Mixed-Integer Nonlinear Problem

MOO: Multi-Objective Optimization Approach

RD: Royal Decree

RDL: Royal Decree-Law

RES: Renewable Energy Source

SES: Spanish Electricity Sector

SoC: State of Charge

(c) <2019>. This manuscript version is made available under the CC-BY-NC-ND 4.0 


\section{Indexes, parameters and variables}

\section{Indexes}

$h$ : time intervals within a day

$t$ : RES generators in the microgrid

$t l:$ electric appliances in the microgrid

ts: ESSs in the microgrid

\section{Parameters}

$A E_{-}$Grid: daily energy term of the access tariff cost [€/Wh]

AP_Grid: daily power term of the access tariff cost [€/W]

$C F_{-} G_{t}$ : fixed generation cost per unit of rated power of an RES $t[€ / \mathrm{W}]$

$C F_{-} S t_{t s}:$ fixed storage cost per unit of rated power of an ESS $t s$ [€/W]

$C V_{-} G_{t}$ : variable generation cost per unit of energy of an RES $t$ [€/Wh]

$C V_{-} S t_{t s}:$ variable storage cost of an ESS $t s[€ / \mathrm{Wh}]$

E_Charges, P_Charges: daily energy and power charges defined by the RD 900/2015 according to the voltage level and type of self-consumption scheme [€/Wh] and [€/W]

Nts: total number of ESS in the microgrid

$P_{R}$ : rated power of the consumer's facility [W]

$P G T_{-}$Max $_{t}$ : maximum power of an RES $t[\mathrm{~W}]$ 
This accepted manuscript does not include other publisher value-added contributions such as copyediting, formatting, technical enhancements and (if relevant) pagination.

PST_Maxts, PST_Mints: maximum positive (charge) and minimum negative (discharge) values of $P S T_{t s, h}$ when $S o C_{t s, d, h} \leq S o C_{-} t h_{t s}[\mathrm{~W}]$

$P S T_{-} t h 1_{t s}, P S T_{-} t h 2_{t s}$ : positive (charge) and negative (discharge) limited values of $P S T_{t s, h}$ when So $C_{t s, d, h}>$ SoC_th $t$ ts $[\mathrm{W}]$

$P S T_{-} N_{t s}:$ nominal power of an ESS ts [W]

$P S_{-} C_{-} t h_{t s}, P S_{-} E_{-} t h_{t s}:$ limited values of $P S_{-} C_{-} t h_{t s, h}$ and $P S_{-} E_{-} t h_{t s, h}$ when $S o C_{t s, d, h}>S o C_{-} t h_{t s}[\mathrm{~W}]$ $P S_{-} C_{-} \operatorname{Max}_{t s}, P S_{-} E_{-} M_{a x}$ : $:$ maximum values of $P S_{-} C_{-} t h_{t s, h}$ and $P S_{-} E_{-} t h_{t s, h}$ when $S o C_{t s, d, h} \leq S o C_{-} t h_{t s}[\mathrm{~W}]$ SoC_Maxts, SoC_Min $t s$ : cap and floor values of $S o C_{t s, h}$ for an ESS $t s$ SoC_th $h_{t s}$ : threshold value of $S o C_{t s, d, h}$ from which $P S T_{-} M a x_{t s}$ and $P S T_{-} M_{i n}$ are limited to $P S T_{-} t h 1_{t s}$ and PST th2 $2_{t s}$

So $C_{t s, 0}$ : the initial conditions of the ESS ts

$\Delta h$ : duration of the time intervals $h[\mathrm{~h}]$

$\varphi_{t s}:$ parameter of the ESS ts

Variables

$C F_{-} G$ : daily fixed generation cost [€]

CF_St. daily fixed storage cost [€]

$C S A_{h}$ : auxiliary consumption related to the RES generators and ESS within the hour $h$ [Wh]

CT_EGT: daily total generation cost [€]

$C T \_S t:$ daily total storage cost $[€]$

$C V_{-} G$ : daily variable generation cost [€]

$C V_{-}$St. daily variable storage cost $[€]$

$C_{-} E G_{h}$ : cost of the energy supplied by the grid within the hour $h$ [€/Wh]

$C_{-} E G T_{t h}$ : cost of the energy supplied by a RES generator $t$ within the hour $h$ [€/Wh]

(C) $<2019>$. This manuscript version is made available under the CC-BY-NC-ND 4.0 
This accepted manuscript does not include other publisher value-added contributions such as copy-

editing, formatting, technical enhancements and (if relevant) pagination.

$C_{-} E H C_{h}$ : aggregated consumption of the consumer within the hour $h$ [Wh]

$D H_{h}$ : consumer's demand within the hour $h[\mathrm{Wh}]$

$E G_{h}$ : energy consumed from the grid within the hour $h[\mathrm{Wh}]$

$E G E_{h}$ : net generation related to the power generation line of the facility within the hour $h$ [Wh]

$E G T_{h}$ : energy supplied by the RES generators within the hour $h$ [Wh]

$E G T_{t, h}$ : energy supplied by a RES generator $t$ within the hour $h[\mathrm{Wh}]$

$E H C_{h}$ : energy consumption related to the power generation line of the facility within the hour $h$ $[\mathrm{Wh}]$

$E L_{t l, h}$ : energy consumption of the appliance $l$ within the hour $h[\mathrm{Wh}]$

ELosses $h$ : average energy loss in the microgrid within the hour $h[\mathrm{Wh}]$

Energy_M1, Energy_M2: daily energy measured by meter 1 and by meter 2, respectively, under the self-consumption scheme $[\mathrm{Wh}]$

Energy_M1 $1_{h}$ : energy measured by meter 1 under the self-consumption scheme within the hour $h$ $[\mathrm{Wh}]$

$E S T_{t s, h}$ energy charged (positive) or discharged (negative) of the ESS ts within the hour $h$ [Wh]

$E S_{-} C_{h}$ : energy charged to all the ESS within the hour $h[\mathrm{Wh}]$

$E S C_{t s, h}:$ energy charged to the ESS ts within the hour $h[\mathrm{Wh}]$

$E S_{-} E_{h}$ : energy discharged from all the ESS within the hour $h[\mathrm{Wh}]$

$E S_{-} E_{t s, h}:$ energy discharged to the ESS ts within the hour $h[\mathrm{Wh}]$

$E X_{-} C_{h}$ : consumption of the overall facility within the hour $h[\mathrm{Wh}]$

$E X_{-} E_{h}$ : energy injected into the grid within the hour $h[\mathrm{Wh}]$

fepp $p_{\text {: }}$ purchased energy final price within the hour $h[€ / \mathrm{Wh}]$

(C) <2019>. This manuscript version is made available under the CC-BY-NC-ND 4.0 
This accepted manuscript does not include other publisher value-added contributions such as copy-

editing, formatting, technical enhancements and (if relevant) pagination.

IMP_EGE: daily cost of the tax set by the Law 15/2012 [€]

$I M P_{-} E X_{-} E$ : sum of the costs of the charges and taxes applied to electricity producers under a

Type II self-consumption scheme [€]

IMP_INC: daily cost from the charge set by the RDL 14/2010 [€]

$I N C \_$Self. daily income related to the energy injected into the grid $[€]$

$P m_{h}$ : daily market price within the hour $h[€ / \mathrm{Wh}]$

$P G_{h}$ : power provided by the grid within the hour $h[\mathrm{~W}]$

$P G T_{t, h}$ : power provided by the RES $t$ within the hour $h[\mathrm{~W}]$

PGT_curt $t_{t, h}$ : power of a RES $t$ within the hour $h$ curtailed from $P G T_{-} M_{a x}$ [W]

Power_M1, Power_M2: daily power measured by meter 1 and by meter 2, respectively, under the self-consumption scheme [W]

$P S T_{t s, h}$ : charged (positive) or discharged (negative) power of the ESS ts within the hour $h$ [W]

$P S_{-} C_{t s, h}:$ charged power in the ESS $t s$ within the hour $h[\mathrm{~W}]$

$P S_{-} E_{t s, h}$ : discharged power in the ESS ts within the hour $h[\mathrm{~W}]$

$P V G_{N}$ : rated power of the generation facility [W]

Status $_{t s, h}$ : binary variable activated when $S o C_{t s, h} \geq S o C_{-} t h_{t s}$

So $C_{t s, h}$ : state of charge of the ESS ts within the hour $h$

(C) $<2019>$. This manuscript version is made available under the CC-BY-NC-ND 4.0 
This accepted manuscript does not include other publisher value-added contributions such as copyediting, formatting, technical enhancements and (if relevant) pagination.

Table list

Table 1. State of the art of microgrid research. Source: self-elaboration based on [3, 4].

Table 2. Parameters related to the ESS model.

Table 3. Parameters of the microgrid

\section{Figure list}

Figure 1. Conceptual definition of the consumer's total energy cost. Source: Self-elaboration.

Figure 2. Electric scheme and conceptual definition of the energy cost for a generalized low voltage consumer with a Type I self-consumption facility. Source: Self-elaboration based on [106].

Figure 3. Methodology applied in the research study. Source: Self-elaboration.

Figure 4. Electrical scheme according to RD 900/2015 for a low voltage consumer with rated power equal or less than 100kW. Source: Self-elaboration based on [106].

Figure 5. Conceptual approach of the problem description. Source: Self-elaboration.

Figure 6. HiL implementation and experimental setup.

Figure 7. EMS solution applied to the facility under study according to the former model and its experimental results. Source: Self-elaboration.

Figure 8. EMS solution applied to the facility under study according to the Type I selfconsumption scheme and its experimental results. Source: Self-elaboration.

(C) $<2019>$. This manuscript version is made available under the CC-BY-NC-ND 4.0 
This accepted manuscript does not include other publisher value-added contributions such as copyediting, formatting, technical enhancements and (if relevant) pagination.

Figure 9. EMS solution applied to the facility under study according to the Type II selfconsumption scheme and its experimental results. Source: Self-elaboration.

(C) <2019>. This manuscript version is made available under the CC-BY-NC-ND 4.0 